\title{
SIGNIFICADO LINGÜISTICO. VERDAD Y VALIDEZ NORMATIVA
}

\section{(La fuerza social vinculante del habla a la luz de una pragmática trascendental del lenguaje)*}

\section{Karl - Otto Apel}

\section{I.- Exposición de la problemática anunciada en el título}

En lo que sigue se establecerá una relación entre los tres conceptos filosóficos fundamentales expuestos en el título. Comencemos con los conceptos que se expresan con los términos "significado" y "validez". ¿Qué relación podría existir entre el concepto de significado y el de validez?

Una primera respuesta podría ser la siguiente: el significado es una especie del género validez. Esto vale en todo caso con respecto al significado lingüístico. Podríamos decir en efecto que el lenguaje es precisamente aquella institución constitutiva de todo lo que pertenece al sentido intersubjetivamente válido, -o mejor, es la metainstitución de todas las instituciones que pueden llegar a ser fundadas por los seres humanos-. Precisamente a este sentido intersubjetivamente válido es a lo que llamaré en adelante "significado". Lo que tengo en cuenta primariamente con esto no es el significado de las palabras sino el significado de las oraciones, el que a veces es llamado sentido de las oraciones. Hablo sin embargo más bien del "significado de las oraciones" precisamente porque de lo que se trata aquí no es del sentido subjetivo, o referido a un sujeto, sino justamente del significado lingülstico, que es intersubjetivamente válido.

Sin embargo, con el término validez se entiende en general en la filosofía, no simplemente la validez del significado tal como se

\footnotetext{
* Traducción del alemán: J. De Zan.

Este trabajo aparecerá próximamente como Cap. I en: K.-O. Apel, Semiótica Filosófica, Ed. Almagesto, Bs. As. Agradecemos a la Editorial la autorización para esta publicación como anticipo del nuevo libro del K.-O. Apel.
} 
halla fijado a través del uso del propio lenguaje, sino algo que va más allá de esto: algo que tiene que ver con la referencia del lenguaje al mundo, como por ej. la validez de las oraciones proposicionales en el sentido de la verdad. Recién con esto aparece evidentemente la posibilidad de plantear la cuestión sobre las relaciones -externas $o$ internas- entre significado lingüístico y validez, y la posibilidad de tematizar, al mismo tiempo, la referencia del lenguaje al mundo. En caso que exista -como es de suponer- una relación intrínseca entre significado y verdad de las oraciones lingüísticas en el sentido de la referencia al mundo implicada en ambos términos, debería resultar entonces de aquí la posibilidad de una explicitación recíproca del sentido de estos términos claves de la filosofía del lenguaje que estamos tematizando. De aquí deberíamos por lo pronto partir.

Ahora bien, el problema de la relación interna entre el significado de las oraciones y la verdad ha sido reconocido en la filosofía analítica ya desde hace mucho tiempo como el punto de partida para la posible explicitación del significado de las oraciones, -incluso en el sentido que, a partir de esta explicación, se ha pretendido establecer la posibilidad de una diferenciación entre oraciones con sentido y oraciones sin sentido.

Así leemos por ejemplo en la famosa proposición 4.024 del Tractatus Logicophilosophicus del joven Wittgenstein: "Entender una oración significa saber qué es el caso cuando ella es verdadera".

Detengámonos un momento en esta tesis sobre la relación entre el significado de las oraciones y la verdad. ¿Qué se quiere decir con esto?

La tesis no ha sido comprendida correctamente la mayoría de las veces por los contemporáneos, sino que ha sido tomada más bien en el sentido de una sobreinterpretación productiva, que considerada en sentido extricto resulta falsa. Se la ha entendido, en efecto, como si Wittgenstein hubiera escrito: "Entender una oración significa saber qué es lo que se mostraría como empíricamente observable, si ella se pudiera demostrar como verdadera". O más brevemente: "comprender una oración significa saber bajo qué condiciones ella se podría veri- 
ficar". Y formulada de manera todavía más sintética y más fuerte: "El significado de una oración es el método de su verificación".

En este caso el veredicto del Tractatus contra toda metafísica como sin sentido sería idéntico con la condena neopositivista de toda metafísica como carente de sentido. $Y$ de hecho, si nos atenemos al testimonio de Friedrich Waissmann habría sido Wittgenstein el primero en formular después de la aparición del Tractatus -alrededor de 1929- el principio de verificación del neopositivismo, como criterio de la comprensión del significado de las oraciones del lenguaje (1).

Sea como fuere, la citada proposición del Tractatus parece traer a colación más bien una posición algo diferente, que está más cercana a Frege (y a Bolzano). En efecto, en la oración que dice: "Entender una oración significa saber qué es el caso cuando ella es verdadera", se deja enteramente indeterminada la cuestión acerca de si es también posible de hecho, o en principio, verificar toda oración susceptible de ser verdadera. Conforme al Tractatus, el que uno pueda saber lo que es el caso, sobre la base de la comprensión de una oración verdadera, se funda en la función representativa de las oraciones elementales verdaderas que ha sido postulada a priori, y en la lógica de las funciones de verdad que hace posible la comprensión de las oraciones más complejas. (De hecho ha sido mostrado también por Karl Popper, y antes ya por Charles Peirce, que los enunciados de leyes universales, por ejemplo, en principio no pueden ser nunca definitivamente verificados. Así como tampoco las oraciones existenciales del tipo "hay una $\mathrm{x}$ ", pueden ser nunca definitivamente falsadas -por más improbable que pueda ser que nos encontremos un día con un caballo alado o una bruja en el sentido de la clásica definición prefeminista del siglo XV). Al igual que Frege y Bolzano, Wittgenstein ha hecho abstracción por lo tanto en la tesis del Tractatus del problema de la verificación o de la falsificación.

(1) Cfer. L. Wittgenstein. Schrifften III: Ludwing Wittgenstein und der Wiener Kreis. Frankfurt, a.M., 1967, p. 243, ss. 
Ahora bien, esta posición abstraccionista conlleva empero algunas dificultades si se pretende hacer de ella algo filosóficamente obligatorio. Lo cual se muestra de manera especial en el caso de Bolzano. Este ha llegado a afirmar, como se sabe, -al igual que ya antes Tomás de Aquino- que los "enunciados en sí" podrían ser verdaderos o falsos de manera enteramente independiente del hecho que se de o no en general algún conocimiento humano -y por lo tanto independientemente también de toda verificación o falsificación (2).

Según mi modo de ver, esta tesis cobra sentido sin embargo solamente bajo un determinado presupuesto: bajo el presupuesto que en Tomás de Aquino está dado por sobreentendido, a saber: que existe por cierto, de todos modos, como sujeto del conocimiento y de esta manera también de la verdad, el "intellectus divinus", que crea el mundo al conocerlo y lo conoce al crearlo. Pero si uno pone entre paréntesis esta presuposición metafísica, entonces la tesis de Bolzano sobre los "enunciados en sí" que pueden ser verdaderos o falsos, implica una "falacia abstractiva" ("abstractive fallacy"). Por cuanto dicha tesis viene a hipostasiar, a la manera platónica, un reino de entidades -a saber: los enunciados verdaderos o falsos en sí-, los cuales pueden ser tematizados haciendo abstracción del conocimiento humano, pero solamente por conveniencia metódica, en cuanto objetos de una semántica lógica-formal.

Si se concibe el hecho de no considerar el conocimiento humano como una simple abstracción metódica que resulta útil para la semántica lógica, entonces se puede decir correctamente que las oraciones (o más precisamente los enunciados proposicionales) pueden ser verdaderos o falsos independientemente del conocimiento fáctico de cualquier hombre determinado, -por lo tanto aún en el caso en que nadie haya siquiera formulado hasta ahora la oración correspondiente. Pero con esto se presupone ahora que en principio es posible el conocimiento humano de la realidad. Y por encima de ello se presupone

(2) B. Bolzano. Wissenschaftlehre, 4 tomos. edit. por W. Schultz, Leipzig, 192933, I, 112. 
todavía algo más, para que sea posible la abstracción metódica de la semántica lógica con respecto al conocimiento fáctico: 1) que se da ya siempre de alguna forma el conocimiento verdadero, 2) que normalmente se sabe cómo comprobar si una pretensión de conocimiento puede rescatarse, es decir, por lo tanto: cómo se puede verificar un enunciado con pretensión de verdad.

Pero de esto se sigue todavía que en la filosofía -es decir, si uno no quiere ocuparse de mera semántica lógica, bajo una expresa abstracción reflexiva de toda cuestión ontológica y epistemológica- se debe presuponer que es posible en principio y que se da también siempre ya efectivamente algo ast como un verdadero conocimiento de la realidad (y no solamente, por otro lado, de "meras apariencias" de realidad). De todo esto se infiere también que la consideración del conocimiento humano en la tematización del significado lingüístico y de la verdad, no puede quedar relegada, como pretende Frege, a una mera cuestion de la psicología, ni como quiere Carnap, a una Pragmática que tiene una relevancia meramente empírica como ciencia particular, sino que debe corresponder por principio al tema propio de la filosofia. Y con esto nos estamos refiriendo también a la consideración de la problemática del sujeto, y de la posibilidad de la verificación y de la falsación. La temática del significado lingüístico y de la validez en cuanto verdad se conecta, en síntesis, por principio, en el marco de la filosofía, con la temática del lenguaje, del conocimiento y del mundo. Y por lo tanto, la abstracción de los temas ontológicos, epistemológicos, o relativos a la teoría del sujeto, tal como fue planteada en la filosofía analítica, por lo menos en su etapa primitiva, y también en el estructuralismo, o bien se ha de interpretar como de relevancia meramente metodológica, es decir, provisional, o sino deriva en una "abstractive fallacy".

Con las reflexiones que acabamos de esbozar sobre la necesidad de poner al descubierto las abstractives fallacies, y de anular las abstracciones metódicas en la filosofía, he introducido ya los indicios del planteamiento crítico de una pragmática trascendental del lenguaje, 
o de una semiótica trascendental (3). En lo que sigue quisiera ensayar nuevamente la aplicación heurística de ese planteamiento (4).

Para comenzar quisiera retomar la problemática de la comprensión del significado de las oraciones en la filosofía analítica. Si mis reflexiones sobre Bolzano y Frege son correctas, entonces se sigue que Wittgenstein estaba en el camino acertado cuando alrededor de 1930 tenía en cuenta como condición de la comprensión de los enunciados proposicionales, no solamente la posibilidad de pensar abstractivamente cuál debe ser el caso cuando el enunciado es verdadero, sino también en principio la posibilidad de la verificación. En este contexto quisiera entender por cierto la verificación en un sentido más amplio que lo que lo hizo el neopositivismo. En un sentido tan amplio de comprobación por medio del conocimiento que permita pensar también la comprobación de enunciados matemáticos, e incluso de enunciados filosóficos con pretensiones de validez universal a priori.

Se entiende que bajo estas condiciones se presupone también en principio la posibilidad de la comprobación in the long run incluso en el caso de los enunciados legales, aún cuando no pueda pensarse en una resolución definitiva. Parto aquí con Ch. Peirce del principio crítico de que los conceptos de realidad y verdad (en el sentido más amplio posible) pueden ser pensados ciertamente con independencia del presupuesto de la resolución fáctica de las pretensiones de verdad a través dell conocimiento, pero no con independencia del concepto de la resolución posithle de dichas pretensiones de verdad por el conoci-

(3) Cfer.: K.-O. Apel, "Zur Isee einer transzendentalen Sprachpragmatik. Die Dreistelligkeit der Zeiche:urelation und die "abstractive fallacy" in den Grundlagen der klassischen Transzendentalphilosophie und der spractanalytiscten Wissenschaftslogik", en J. Simon (Ed), Aspckte und Probleme der Sprachphilosophie, Freigurg, 1974, p. 283-326 (Hay irad. castellana: J. Simon (Ed) Aspectos y Problemas de la Filosofia del Lenguaje, Edit. Alfa. Barcelona). Cfer. también: K-O.Apel. "Pragmatische Sprachphilosophie in transzendentalsemiotischer Bergründung, en H. Stachowiack (Ed.), Pragmatik Bd. IV, Teil I, Hamburg, Meiner, por aparecer ocmo cap. II. del libro citado al comienzo, en la ref. sobre el origen de exte texto.

(4) Cfer. H. G. Gadamer, Wahoheit und Methode, Tübingce, 1960. Kegistrer: "Abstraction". 
miento (5). Esto implica, naturalmente, entre otras cosas, que no puede pensarse con sentido en cosas en sí incognoscibles por principio. Dicho de otra manera: el concepto de la cognoscibilidad, o del conocimiento posible en principio ha de ser concebido en el sentido de una idea regulativa, a la cual no puede corresponder nada empírico bajo las condiciones de la finitud. Tenemos por cierto buenas razones para presuponer que bajo las condiciones de la finitud, la realidad en su verdad no podrá ser nunca de hecho definitivamente conocida. Esto es lo que podemos retener como correcto del punto de vista crítico de Kant. Pero esto no implica, de ninguna manera, que pueda concebirse una realidad en principio incognoscible, o un concepto de verdad independiente del concepto de conocimiento.

Podría sintetizar por lo tanto mi referencia anterior a Wittgenstein en el sentido de la fórmula siguiente: entre el concepto de significado lingǘstico de las oraciones y el concepto de la verdad puede establecerse una relación en el sentido de un verificacionismo entendido de manera muy amplia. En este sentido quisiera interpretar también el planteo difundido en la filosofía analítica de la explicitación del significado de las oraciones del lenguaje en términos de condiciones de verdad. Sin embargo, ¿qué tiene que ver este planteo con la relación enunciada en el título entre significado lingüístico y validez?

Ya desde el comienzo he indicado que quisiera entender la verdad como un caso especial, o mejor, como una dimensión de la validez intersubjetiva del significado articulado lingüísticamente. Conforme a esto se plantea la posibilidad, e incluso la exigencia, de una ampliación de la explicación que se ha dado hasta ahora del significado lingüístico de las oraciones y de su comprensión posible. Esta ampliación llevaría a plantear la cuestión no ya en los términos de las condiciones de verdad, sino de las condiciones de validez. ¿Cómo se puede entender y fundamentar ahora esto? De lo que se trata ahora es de revertir filosóficamente toda una serie de abstracciones metódicas, que han mantenido todavía su vigencia en la filosofía analítica del lenguaje,

(5) Cfer.: K.-O.Apel. Der Denkweg von Charles Peirce. Frankfurt a. M. 1975, p. 51 , ss. 
incluso allí donde sus presupuestos han sido en parte superados. Quisiera mostrar esto en lo que sigue con ayuda de los logros de la teoría de los actos de habla.

\section{II.- El problema de la explicitación del significado de las oraciones o de los actos de habla no constatativos en la filosofía analítica del lenguaje}

La teoría de los actos de habla de Austin y de Searle, así como la teoría de los juegos de lenguaje del Wittgenstein tardío, han puesto en claro lo siguiente: el significado de las oraciones del lenguaje no se agota en la exposición o descripción de estados de cosas a través de las oraciones proposicionales. Y al afirmar esto no tengo en cuenta solamente el significado en cuanto significado pragmático, referido a un determinado contexto, sino también ya el significado en cuanto semántico, establecido por medio de las convenciones de un sistema lingüístico. Ya Aristóteles había tenido en cuenta que el lenguaje no consta solamente de oraciones enunciativas, sino también, por ejemplo, de oraciones imperativas, de deseo, interrogativas. Por eso ya para él el "semantikos logos" no era idéntico al "apophantikos logos" (6). Con la teoría de los actos de habla este punto de vista ha alcanzado una diferenciación esencialmente más amplia. Por cuanto se ha mostrado además que las propias oraciones enunciativas, en tanto ellas fijan, de acuerdo a las convenciones lingüísticas, actos de habla constatativos o de afirmación, no constan solamente de una parte proposicional, que representa estados de cosas, sino también de una parte performativa que determina de manera convencional la "fuerza ilocucionaria" de la oración bajo las condiciones de situaciones normales, como lo señala Austin (7). John Searle ha desarrollado más ampliamente este planteo en su libro Speech Acts, de 1969 (8).

(6) Aristóteles, De Interpretatione, 4, 16b 33 - 17a 4.

(7) Cfer.: J.L.Austin, Ilow to do Things with Words,. Oxford Univ. Press; 1971.

(8) J.R. Searle, Speech Acts, Cambridge University Press, 1969., Ed. alemana Sprechakte, Frankfurt, 1971. (hay trad. castellana, Actos de habla, ed. Cátedra, Madrid, 1986). 
Sobre la base de los mencionados trabajos se esclareció lo siguiente: si uno formulara explícitamente las oraciones, no solamente en el sentido de su contenido proposicional, sino también en el sentido de su aspecto performativo, entonces se podría comprobar que todo tipo de oraciones consta de una doble estructura performativo-proposicional (9). Las oraciones simples, pero diferentes desde el punto de vista modal, se descomponen entonces en dos partes conforme a la doble estructura explicitada: la diferencia modal se puede retrotraer a la diferencia de la oración elemental performativa, micntras que la oración elemental de contenido proposicional que expone con vcrdad o falsedad un estado de cosas, puede permanecer idéntica. Así, tenemos, por ejemplo, la siguiente serie de oraciones:

$\begin{array}{llll}\text { "Yo constato } & \text { por este medio que } & p^{n} & \text { (por ej: la puerta está abierta). } \\ \text { "Yo afirmo } & \text { por este medio que } & p^{n} . & \\ \text { "Yo ordeno } & \text { por este medio que } & p^{n} & \text { ha de ser ejecutado. } \\ \text { "Yo prometo } & \text { por este medio que } & p^{n} & \text { ha de ser ejecutado. } \\ \text { "Yo confieso } & \text { por este medio que } & p^{n} & \text { ha sido hecho (por mú). } \\ \text { "Yo pregunto } & \text { por este medio si } & p \text { ". } & \end{array}$

Con estos ejemplos se ve claramente que la fuerza ilocucionaria del acto del habla, que se hace efectiva en cada caso mediante la expresión de la oración completa en condiciones de contexto normales, está determinada por la respectiva parte perfomativa de la oración. Y de esta manera queda claro también que por lo menos una parte del significado lingüístico de las oraciones no reside en la función expositiva de la parte proposicional de la oración, sino que está constituido por la función de la respectiva parte de la oración de carácter performativo, -función esta última que es responsable de la fuerza ilocucionaria del acto del habla posible.

¿Qué consecuencias tiene ahora este punto de vista semántico para la posible ampliación de la explicitación del significado de las oraciones del lenguaje en general?

(9) Cfer.: J. Habermas, Was heißt Universalpragmatik?, en K,.O. Ape:l (Edit.), Sprachpragmatik und Philosophie, Frankfurt a. M., 1976, 174-272; Cfer. también, K:-O. Apel, cap. I del mismo libro. 
Para anticipar primero la respuesta en forma de tesis se puede decir que: como se mostrará, el significado lingüístico de las partes performativas de las oraciones, a diferencia del significado de las partes proposicionales, no puede ser explicitado en los conceptos de las condiciones de verdad, sino más bien en cambio por medio del concepto de condiciones de validez en cuanto condiciones de aceptabilidad. ¿Qué se quiere decir con esto?

Si es correcto que las condiciones de verdad de la parte de contenido proposicional de las oraciones forman un caso especial de las condiciones de validez de las oraciones en su doble estructura, entonces debería existir evidentemente por un lado algo en común, y por otro una diferencia específica entre las dos posibilidades de explicitación que ahora se ponen en discusión.

Lo dicho equivale a sostener la tesis que, en analogía al Tractatus de Wittgenstein, podría ser formulada de la siguiente manera: Entender una oración performativo-proposicional significa saber cuáles son las condiciones de su posible validez, es decir, de su aceptabilidad.

Para elucidar la problemática del programa de explicitación que hemos enunciado, y para mostrar que su realización presupone la superación de toda una serie de "abstracrtive fallacies", quisiera acometer aquí una breve discusión crítica de algunos intentos de resolver el problema del significado de las oraciones no constatativas, realizados por la filosofía analítica del lenguaje. Se puede mostrar que ésta se ha aferrado obstinadamente al modelo de explicación en los términos de condiciones de verdad, y que incluso los propulsores de la teoría de los actos de habla, que han intentado tener en cuenta la diferencia entre entender el significado proposicional y entender la fuerza ilocucionaria, no se han podido liberar del paradigma de las condiciones de verdad.

II. 1. Peter Strawson se preocupa así, por ejemplo, de dar razón de la diferencia y de la analogía entre la comprensión de las oraciones constatativas, y la comprensión de las no constatativas mediante la introducción del concepto de "condiciones de realización". El parte en primer lugar del hecho que las expresiones cons- 
tatativas y las no constatativas, como por ej. "una orden y un enunciado pueden tener el mismo contenido (proporcional), y cuando este es el caso se presentan en ambos en sentido general los mismos elementos referenciales y los mismos elementos de predicación". A esa totalidad de referencia y predicación que surge en los dos casos la llama pensamiento ("thought"). Con respecto a ello comprueba entonces que: "no se podría decir que los pensamientos tengan un valor de verdad, porque este le corresponde solamente a los enunciados, y el pensamiento es algo que puede ser común por ejemplo a un enunciado, a una orden y a una promesa. Pero justamente de la misma manera como está en la naturaleza de un enunciado el ser verdadero o falso, así también pertenece a la naturaleza de una orden el ser o no ser obedecida, y a la naturaleza de una promesa el ser o no ser cumplida. De esta manera podemos decir nosotros que corresponde al pensamiento un valor de realización: un valor de realización positivo cuando el enunciado es verdadero, la orden es obedecida y la promesa es cumplida; y un valor de realización negativo cuando el enunciado, la orden, la promesa, en los cuales dicho valor se manifiesta, son respectivamente: falso, o no es obedecida, o no se cumple" (10) (Subrayado: K-O Apel).

Aquí se ha aprovechado evidentemente la analogía que existe entre condiciones de verdad y condiciones de realización en el sentido de la teoría de la verdad como correspondencia. Puesto que para comprender un enunciado uno debe saber bajo qué condiciones él sería verdadero, así también en el caso de una orden o de una promesa: bajo qué condiciones el contenido proposicional sería realizado, es decir, se haría verdadero. En esto reside sin dudas una condición necesaria de la comprensión de las órdenes y las promesas -en lo que respecta a sus particulares

(10) Strawson, Einzelding und logische Subjekt (Individuals), Stuttgart, 1972, 313 ss. Cfer. también el artículo "Meaning and Truth", en "Logico-linguistic Papers", (London, 1971), donde se lee: "...in almost all the things we should count as sentences there is a substantial core of meaning wich is explicable either in terms of truth-conditions or in some related notion quite simply derivable from that of a truth-condition, for example the notion, as we might call it, of a compliance-condition in the case of an imperative sentence or a fulfilment-condition in the case of an optativen (p. 178). 
contenidos proposicionales. Pero, ¿se ha dado con esto también ya una condición suficiente para la comprensión del significado performativo de las ordenes y de las promesas -por lo tanto de su posible fuerza ilocucionaria? ¿Se puede sin más prestar asentimiento a la siguiente fórmula: comprender adecuadamente una orden en cuanto orden significa saber cuáles son sus condiciones de realización? ¿O a esta otra: comprender adecuadamente una promesa en cuanto promesa significa saber bajo qué condiciones sería cumplida?

Si así fuera, ¿cuál sería entonces la diferencia de significado entre una orden y una promesa? ¿o entre una orden, un pedido, una exigencia, y una intimación apoyada en la fuerza, como "jarriba las manos!", "¡la bolsa o la vida!"? El contenido proposicional puede ser por cierto idéntico en todos estos casos, y de esta manera pueden ser también idénticas las condiciones de realización que se tratan de entender. Pero sin embargo no se habrían entendido con esto en absoluto las diferentes fuerzas ilocucionarias de los distintos actos de habla.

Habría que preguntar: ¿qué es lo que ha entendido adicionalmente el destinatario que no respeta una orden, al replicar, por ej.: "Ud. no tiene nada que ordenarme a mí!"?, o aquel que declara: "Yo rehuso la ejecución de vuestro mandato por motivos de conciencia". O aquel otro que dice: "Mira, haré sí lo que me exiges porque soy tu amigo, pero no porque me lo hayas ordenado". O el oportunista, que cumple una orden, pero pensando para sí: "la orden es por cierto ilegal (o inmoral), pero si no la acato tendré un disgusto".

Bastan estos ejemplos, que se refieren solamente a actos de habla directivos, para llamar la atención sobre el hecho que por lo menos el destinatario de actos de habla no asertóricos tiene que entender todavía, además de las condiciones de realización del significado proposicional, también las condiciones de validez o de aceptabilidad bajo las cuales los actos de habla directivos cobran normalmente su fuerza ilocucionaria y, por lo tanto, en el caso de oraciones con una doble estructura explícita, tiene que entender también el significado de la parte performativa de las oraciones. 
Más allá de esto se puede afirmar todavía que, incluso en el caso de los actos de habla asertóricos debe comprender el destinatario en sentido estricto algo más que solamente las puras condiciones de verdad del contenido proposicional. A saber, él debería comprender también todavía que el hablante que afirma algo como verdadero se cree autorizado a plantear al destinatario la exigencia de: o bien aceptar como verdadero lo afirmado (la proposición), o bien impugnarlo con fundamentos. Con esto se habría entendido, también en el caso de un acto de habla asertórico, el significado performativo a la luz de las condiciones de validez o de aceptabilidad y evidentemente sólo una explicación del significado realizada en estos términos habría tomado plenamente en consideración la diferencia entre el significado proposicional y el performativo-ilocucionario, que es válida para todo acto de habla, también para las afirmaciones y los constatativos.

En este punto se plantea sin embargo todavía la pregunta siguiente: ¿por qué en el caso de las afirmaciones o de los constatativos no juega aparentemente ningún rol la diferencia entre el significado proposicional y el performativo, mientras que para las órdenes, pedidos, promesas, etc., parece jugar un papel tan decisivo? Dicho de otra manera: ¿por qué en el caso de los constatativos o de las afirmaciones, la comprensión de las condiciones de verdad de la parte proposicional de las oraciones puede aparecer como una comprensión suficiente del completo significado de la oración expresada, y de esta manera también del acto de habla, mientras esto aparece manifiestamente en el caso de las no asertóricas como insuficiente?

Una respuesta provisoria a esta pregunta podría ser la siguiente: en el caso de los actos de habla constatativos o asertóricos, no parece ser posible una discrepancia entre la explicitación del significado proposicional y la del significado performativo-ilocucionario. Cuando la proposición afirmada se ha comprobado como verdadera, puede ser considerada también como resuelta la pretensión de validez del acto de habla, propuesta en su parte performativa. En el caso de los actos 
de habla no asertóricos, en cambio (de los cuales hemos considerado nosotros hasta ahora solamente los directivos), la cosa es enteramente diferente. Aquí el cumplimiento fáctico de las condiciones de verdad del contenido proposicional -es decir, por ejemplo, la realización (Wahrmachen) de lo ordenado o lo exigido, no tiene manifiestamente nada que ver en absoluto con las pretensiones de validez performativamente propuestas. Esto se muestra especialmente en los casos en que el cumplimiento de una orden o de una exigencia tiene lugar por motivaciones oportunistas. Aquí se puede llegar por lo tanto a una discrepancia entre la explicitación del significado performativo o ilocucionario, que implica la pretensión de validez, y la explicitación del significado proposicional, que depende de las condiciones de realización. Con lo dicho se vuelve a plantear aquí de nuevo la cuestión sobre por qué en el caso de los actos de habla directivos se puede llegar a esta discrepancia, y en el caso de los actos de habla constatativos o asertóricos en cambio no. Tenemos que volver todavía sobre esta cuestión.

Quisiera recordar en primer lugar la circunstancia de que, también en el caso de los actos de habla asertóricos existe no obstante una diferencia desde el punto de vista del análisis de la filosofía del lenguaje, entre el significado proposicional y el performativo-ilocucionario. Si se considera esta circunstancia ahora poniendo especialmente de relieve la diferencia entre condiciones de realización y condiciones de validez en el caso de los actos de habla directivos, se llega así al interesante resultado siguiente:

Debido a su doble estructura performativo-proposicional, el acto de habla asertórico, o la oración afirmativa explícita funciona evidentemente como paradigma para dos dimensiones de la explicitación del significado que son enteramente diferentes. Se trata por una parte de la explicitación del significado proposicional conforme al modelo conceptual de las condiciones de verdad en cuanto caso especial de las condiciones de realización, en el sentido del verificacionismo. Por otra parte, de la explicitación del significado completo performativo-proposicional en los términos de las condiciones 
de verdad entendidas como caso especial de las condiciones de validez o de aceptabilidad, en el sentido de nuestro propio punto de vista (11).

(11) Andreas Dorschel ha expuesto este resultado en el siguiente cuadro, en su artículo "What is it to Understand a Directive Speech Act?" (inédito):

\begin{tabular}{|c|c|c|}
\hline$\underbrace{\text { conditions }}_{\begin{array}{l}\text { cutlo- } \\
\text { categary } \\
\text { categories }\end{array}}$ & $\begin{array}{l}\text { conditions of } \\
\text { validity fullfilled }\end{array}$ & $\begin{array}{l}\text { conditions } \\
\text { of correspondence } \\
\text { between proposition } \\
\text { and reality fullfilled }\end{array}$ \\
\hline $\begin{array}{l}\text { Assertives } \\
\text { (e.g. state, } \\
\text { predict) }\end{array}$ & $\operatorname{true}$ & true \\
\hline $\begin{array}{l}\text { Directives } \\
\text { (e.g. order, } \\
\text { forbid) }\end{array}$ & $\begin{array}{l}\text { (moraly / legaly } \\
\text { right) }\end{array}$ & $\begin{array}{l}\text { complied with } \\
\text { by the hearer }\end{array}$ \\
\hline $\begin{array}{l}\text { Commisives } \\
\text { (e.g. promise, } \\
\text { contract) }\end{array}$ & $\begin{array}{l}\text { (moraly / legaly } \\
\text { right) }\end{array}$ & $\begin{array}{l}\text { kept by the } \\
\text { speaker, } \\
\text { observed by the } \\
\text { contracting parties }\end{array}$ \\
\hline $\begin{array}{l}\text { Declaratives } \\
\text { (e.g. excommunicate, } \\
\text { degrade in military } \\
\text { rang) }\end{array}$ & $\begin{array}{l}\text { (moraly / legaly } \\
\text { right) }\end{array}$ & $\begin{array}{l}\text { succesfully } \\
\text { achleved }\end{array}$ \\
\hline
\end{tabular}

En oposición a Dorchel no tendría yo reparo alguno en complementar cómo sigue el cuadro precedente en el sentido de la tríada habermasiana de las pretensiones de validez y de los respectivos Mundos de referencia.

\begin{tabular}{|l|l|l|}
\hline $\begin{array}{l}\text { Expressives } \\
\text { (e.g. confess, } \\
\text { congratulate) }\end{array}$ & sincere & $\begin{array}{l}\text { corroborated as } \\
\text { corresponding to } \\
\text { one's inner feelings } \\
\text { by one's behaviour }\end{array}$ \\
\hline
\end{tabular}

En el caso del cuestionamiento de la veracidad o de la sinceridad de la expresión de los sentimientos no hay por cierto ninguna posibilidad de resolución de la pretensión de validez por medio de argumentos -por cuanto la veracidad está ya evidentemente presupuesta en toda argumentación, en cierto modo como una actitud previa del argumentante-. Esto no nos impide sin embargo atribuir una pretensión de veracidad, cuyo presupuesto -la correspondencia de lo expresado por el lenguaje con el "mundo interior" del hablante-, puede ponerse en cuestión, protestarse, y puede también comprobarse como existente por medio del obrar cotidiano. 
Las condiciones de verdad son comprendidas por lo tanto como un caso especial de las condiciones de validez si, y sólo si, -a partir de la doble estructura performativo-proposicional de la que constan ya las oraciones afirmativas-, se las considera como condiciones de la validez intersubjetiva o de la aceptabilidad (aptitud para obtener consenso) de los actos de habla. Si se hace abstracción en cambio de la dimensión pragmática de las pretensiones de verdad performativamente propuestas, y de su posible resolución discursivo-comunicativa a través de la formación argumentativa de consenso, es decir, si uno se concentra solamente en la referencia al mundo objetivo de las oraciones proposicionales en cuanto representativas de estados de cosas, en el sentido de la semántica lógica, entonces se hace posible en efecto examinar las condiciones de verdad de las oraciones asertóricas como un caso especial de las condiciones de realización de los contenidos proposicionales de las oraciones en general, y en este sentido se hace posible también explicitar de hecho el significado lingüístico en general conforme al modelo conceptual de un verificacionismo ampliado.

Es llamativo el hecho de que Strawson ha tenido muy bien en cuenta la posibilidad de la explicitación del significado en las dimensiones completamente diferentes que acabamos de mencionar, pero se ha decidido sin embargo contra la sugerencia de Austin por la analogía entre condiciones de verdad y condiciones de realización. Austin había querido sostener en realidad el acto de la afirmación con su totalidad como el portador de la verdad y comprender consecuentemente la verdad de una afirmación como un caso especial del éxito de un acto de habla -en el sentido de la analogía entre verdadera comprobación, buen consejo y mandamiento justo (12). Strawson rechaza sin embargo esta "asimilación" de la verdad al concepto de aceptabilidad de los actos de habla. El insiste en una teoría del significado

(12) Cfr. Austin, op. cit., p. 139 ss.: del mismo: Truth. en G. Pitscher (Ed.). Truth, London, 1969, 16-31. Sobre esto, K-O. Apel, "Austin und die Sprachphilosophie der Gegenwart", en H. Nagl-Docekal (Ed.), Überlieferung und Aufgabe, Wien, 1982, Bd. 1, 183-196. 
orientada al contenido proposicional, entendido como lo único que puede ser verdadero o falso (13).

Una razón fundamental para esta opción es para Strawson -como para muchos otros analíticos, -por ej. Davidson y Dummet-, evidentemente lo siguiente: por un lado ellos no quisieran poner en paralelo la verdad teórica con la justificación de pretensiones de validez prácticas (por ejemplo morales), y por otro lado quisieran reconocer como significado en el sentido de la semántica solamente el contenido proposicional preciso de las oraciones, y no la indicación performativa de la fuerza ilocucionaria posible de la expresión de una oración en el sentido de un determinado tipo de acto de habla. Ellos pretenden concebir evidentemente el significado performativo-ilocucionario como tema de la pragmática que, en cuanto teoría del uso del lenguaje referido a las diversas situaciones, presupone ya el significado proposicional de las oraciones.

Esta posición corresponde en realidad a la antigua diferenciación abstractiva entre semántica y pragmática, que fue impuesta particularmente por Carnap (en conexión con la Foundations of the Theory of Sings de Morris) (14). Según mi modo de ver, se puede mostrar, sin embargo, que esa separación abstractiva entre una semántica referida al sistema lingüístico y una pragmática referida a la aplicación es aplicable solamente a los lenguajes artificiales, pero no a los lenguajes naturales (15). Los últimos, cuyas oraciones presentan, por lo menos implícitamente, una doble estructura performativo-proposicional, pueden predeterminar en la dimensión semántico-convencional la posible fuerza ilocutoria de la oración completa, es decir, la aplicación pragmática posible bajo condiciones situacionales normales. Esto se

(13) Strawson, "Austin on Locutionary Meaning", en Isaiah Berlin (Ed.), Essays on J.L. Austin, Oxford, 1973, 46-68, p. 54 y 65.

(14) R. Carnap. Introduction to Semantics, Cambridge/Mass, 1942, 4 y, del mismo: Meaning and Necessity, Chicago, 1956, esp. "Apendix E".

(15) Cfer. K.-O. Apel, Austin und die Sprachphilosophic der Gegenwart, loc. cit.; y del mismo autor, cap. IV de este libro, por apareceren Ed. Almagesto, Bs. As. 
verifica en el lenguaje natural por medio del componente performativo del significado. Por ej. a través de oraciones elementales como: "yo afirmo por este medio que...", o "yo ordeno por este medio que...". De lo que se trata aquí por lo tanto es nuevamente de superar una abstracción metódica (que fue útil para la semántica constructiva y para la lógica de la ciencia), en vistas a la comprensión del lenguaje natural, que es indispensable para la filosofía. ¿Cómo habría que pensar esto?

II. 2. Considero que nadie ha formulado de manera más clara y categórica que John Searle en su libro Speech Acts de 1969 el programa de la necesaria superación de la separación abstractiva entre la semántica orientada a las oraciones proposicionales y la pragmática de orientación aplicada. El ha escrito allí (16):

"No hay dos clases de investigaciones semánticas en principio diferentes e irreductibles: por un lado un estudio de los significados de las oraciones, y por otro un estudio de las realizaciones de los actos de habla. Pues de la misma manera que forma parte de nuestra noción del significado de una oración el que una sincera emisión de esa oración con ese significado en un cierto contexto significa la realización de un determinado acto del habla, así también forma parte de nuestra noción de un acto de habla el que haya una oración posible (u oraciones posibles), la emisión de la cual (o de las cuales) en un determinado contexto constituye, en virtud de su (o de sus) significado (s) una realización de este acto de habla".

Se encuentra aquí claramente expresado que el componente performativo del significado de la oración, que debe ser objeto de la semántica lingüística, determina al mismo tiempo el significado pragmático del acto de habla, que es realizado mediante la emisión de la oración en condiciones situacionales normales. Esto lo confirma Searle también en su libro más reciente, Foundations of Illocutionary Logic, (Cambridge, 1985), donde escribe: "Part of the meaning of an ele-

(16) J.R. Searle, op. cit., en nota 8. 
mentary sentence is that its literal utterance in a given context constitutes the perfomance or attempted perfomance of an illocutionary act of a particular illocutionary force (...). Every complete sentence, even a one-word-sentence, has some indicator of illocutionary force: therefore no semantical theory of language is complete without an illocutionary component. A materialy adequate semantics of a natural language must recursively assing illocutionary acts (elementary or complex) to each sentence for each possible context of utterance. It is not sufficient for it simply to assign propositions or truth conditions to sentences" (Loc. cit. p. 7).

Este me parece ser un paso importante en la correcta dirección. Tanto más sorprendente resulta entonces el hecho de que Searle en su libro Intentionality, de 1983, sostenga una teoría del significado que se conecta inmediatamente a la de su maestro Strawson, y esto quiere decir, a la explicitación del significado proposicional en los términos de las "condiciones de realización". Searle habla de "condiciones de satisfacción" ("conditions of sastisfaction") con referencia a la intención del significado prelingüística que, según su opinión, determina en última instancia también el significado del acto de habla (17).

Avanzando más allá de Strawson, introduce él, por cierto, una innovación, manifiestamente orientada a hacer comprensible cómo se pone en juego la fuerza ilocucionaria performativamente determinada, y cómo actúa conjuntamente con las condiciones de realización del contenido proposicional de la oración, determinando las condiciones de satisfacción para la intención de significado conectada con el acto de habla. La innovación consiste en la introducción del concepto de una "orientación de adecuación" ("direction of fit") en relación a la correspondencia entre el acto de habla y el mundo, que es constitutiva para las condiciones de satisfacción. Entonces puede decir él que en el caso de los actos de habla constatativos o asertóricos la orientación de adecuación que hay que tener en cuenta para las condiciones de satisfacción toma el carácter de un ajuste de las palabras al mundo

(17) J. R. Searle, Intentionality, Cambridge Univ. Press 1983, ch. 1 y ch. 6. 
("word to world-direction of fit"); en el caso de los actos de habla directivos y comisivos en cambio -es decir, por ej. de las ordenes y las promesas- la orientación de adecuación toma el carácter de un ajuste del mundo a las palabras ("world to word-direction of fit").

Searle puede dar razón con esto incluso de la diferencia entre los actos de habla directivos y los comisivos, a saber: mediante la distinción entre el caso en que es el destinatario quien debe garantizar la satisfacción, como por ejemplo, cuando se trata de órdenes, pedidos o exigencias: y por otro lado el caso en que es el mismo hablante quien se compromete a ello -como por ejemplo por medio de promesas o votos.

Ahora bien, tenemos que preguntarnos a esta altura si a través de esta ampliación de la analogía de Strawson entre condiciones de verdad y condiciones de realización se ha logrado fundamentar efectivamente una teoría del significado que, como el propio Searle lo pretende, sea capaz de dar razón del significado específico de los indicadores performativos de la fuerza ilocucionaria de los actos de habla.

Creo que no se puede decir de ninguna manera que esto se haya logrado, como habré de mostrarlo enseguida mediante algunos ejemplos. Pero con los ejemplos quisiera corroborar al mismo tiempo la tesis siguiente: con su teoría del significado Searle puede dar razón de las diferentes fuerzas ilocucionarias de los actos de habla solamente en el caso que esta fuerza se deje retrotraer a intenciones prelingüísticas. Si se puede mostrar por lo tanto al mismo tiempo que con ello no se explica tampoco la diferenciación de los significados de los actos de habla, entonces esta discusión desemboca en la prueba que, -contra la tesis central de Searle en su libro Intentionality- el significado lingüístico no se deja reducir a significados prelingüísticos en el sentido de la intencionalidad (18).

(18) Para esta crítica del reduccionismo intencionalista del libro de 1983 desde la propia perspectiva del primer Searle, cfer. K-O. Appel, "Linguistic Meaning and Intentionality. The compatibility of the "Linguistic Tum" an the "Pragmatic Turn" of Meaning-Theory within the Framework of a Trascendental Semiotics", en H. Silverman/D. Welton (edts.), Critical and Dialectical Phenomenology, por aparecer. Del mismo autor. "Lässt sich sprachliche Bedeutung auf Intentionalität reduzieren? Das Verhältnis von Sprachapriori un Bewusstseinsapriori im Lichte einer transzendentalen Semiotik bzw. Sprachpragmatik", en M.Benedikt/R.Burger (edts.), Bewußtsein, Sprache und die Kunst, por aparecer. 
Consideremos ahora los siguientes ejemplos:

1) Un soldado rehusa el cumplimiento de una orden con el argumento que ella es ilegal.

2) El mismo rehusa el cumplimiento de una orden porque quien la ha dictado carece de autoridad legítima para darle ordenes a él.

3) El mismo rehusa el cumplimiento de una orden conforme a la ley y emitida por autoridad legítima por motivos de conciencia.

4) El mismo cumple una orden que es ilegal e inmoral porque teme las consecuencias que podría sufrir si rehusara su cumplimiento.

En los tres primeros ejemplos se rehusa el cumplimiento de una orden que -como el destinatario puede presuponerlo- se corresponde con el deseo (o mejor: con la intención de la voluntad) del que manda con respecto a la realización de las condiciones de satisfacción por parte del destinatario de la orden. Bajo este aspecto se puede decir con Searle que la fuerza ilocucionaria de la orden, iniencionalmente condicionada, ha sido entendida. Sin embargo, esa fuerza no ha sido efectiva en el sentido de la aceptación de la orden. ¿Por qué no? Es evidente que la razón está en que el destinatario ha entendido todavía algo más en cada caso que le impide respetar la fuerza ilocucionaria como razón suficiente para el cumplimiento de la orden. En el primero y segundo caso ha entendido que la orden emitida -por diferentes motivos- no es una orden legal o institucionalmente justificada. En el tercer caso ha entendido que, si bien la orden es ciertamente legal, sin embargo, por razones morales no la puede considerar obligatoria para él.

Llegados a este punto todo depende de que se pueda mostrar lo siguiente: que lo que el destinatario ha entendido en nuestros ejemplos, fuera de las condiciones de satisfacción de la intención de la voluntad del hablante, debe formar parte, como puede comprobarse, de la fuerza ilocucionaria, semánticamente significada del acto de habla y, en cuanto tal, debe pertenecer al significado lingüístico de la oración imperativa. Por cuanto en la explicitación del significado lingüístico no se puede tratar de tomar en consideración todo aquello que el respectivo destinatario, por causas contingentes, ha podido entender fácticamente, o también lo que él debe haber entendido conjuntamente, sobre 
la base del contexto lingüístico o del trasfondo de los presupuestos de la respectiva "forma de vida". (En semejante caso, de una superación holística de toda abstracción constitutiva de los objetos no sería ya más posible ninguna teoría del significado. Por cuanto una teoría científica, que quiere ser objetivamente válida, presupone siempre una abstracción de la constitución a priori del objeto). Ahora bien, con referencia a nuestros ejemplos, es posible mostrar empero que el destinatario ha entendido algo que está por cierto más allá de las condiciones de satisfacción de la intención voluntaria del hablante, pero que pertenecía en el sentido indicado a la fuerza ilocucionaria de la orden.

Esto se deja mostrar de manera relativamente fácil para el primero y el segundo ejemplo: Cuando un hablante dice, por ejemplo: "yo le ordeno por este medio ejecutar a los prisioneros", es evidente que él espera que el destinatario entienda esta orden no solamente en el sentido de las condiciones de realización o de las condiciones de satisfacción, sino, más allá de esto, también como una orden legal emitida por persona autorizada para dar tales órdenes. Precisamente esto constituye la diferencia de la fuerza ilocucionaria de su acto de habla con respecto a una súplica, o a una exigencia (ni que hablar de una intimación apoyada en la fuerza). La validez que pertenece a la fuerza ilocucionaria de la orden y forma parte de su constitución, se puede apoyar en este caso en una institución social, y en cuanto tal podría reducirse aparentemente a una vigencia social empíricamente comprobable. En la medida en que esto es así, esta consideración de la pretensión de validez como parte de la fuerza ilocucionaria sería compatible todavía con una teoría del significado lingüístico libre de valoración, y por esta razón resultaría aceptable quizás para muchos lingüistas y científicos sociales que desean evitar implicaciones filosófico-normativas.

Para el planteo que sostenemos aquí y en lo que sigue, es por lo tanto más decisiva la apreciación del tercer ejemplo (y del cuarto, que depende de éste). ¿El soldado que niega acatamiento a la orden de ejecutar a los prisioneros por motivos morales, ha podido entender algo en la orden, por ej., como razón para la negativa de su acatamiento, de tal manera que, como en el caso de la ilegalidad, pueda o deba comprenderse como deficiencia de la fuerza ilocucionaria de la 
orden? Si prescindimos aquí del posible caso de la ilegalidad de la orden en el sentido de la violación de la convención de Ginebra, parece claro que una respuesta positiva a nuestra pregunta es posible solamente bajo el siguiente presupuesto: tiene que ser posible mostrar que pertenece a la comprensión de la fuerza ilocucionaria de una orden en última instancia la apreciación de los fundamentos racionales universalmente válidos que permitan juzgar la obediencia de la orden como fundada o justificada (de la misma manera como ello pertenece a la comprensión de la fuerza ilocucionaria de una exigencia). Esto nos lleva más allá de la vigencia convencional de la autoridad institucional de quien emite la orden, en el sentido incluso de la posible legitimación de esa vigencia. Estas conclusiones serán discutidas por todos aquellos que cuestionan la posible fundamentación moral del derecho, o incluso la fundamentación racional de la moral como definitivamente válida, como los partidarios del positivismo jurídico y otros empiristas de la vigencia fáctica.

No podemos rebatir aquí todavía definitivamente esa posición, pero podemos por lo menos llamar la atención sobre el hecho que, 1) la definitiva validez del cuestionamiento de la posible fundamentabilidad racional de la moral no puede ser afirmada sin contradicción y, 2) evidentemente que actos de habla como las exigencias (por la igualdad de derechos, o por el cumplimiento de promesas o contratos, por ej.), no pueden ser entendidos en absoluto en el mundo de la vida (e independientemente, por cierto, de la respectiva forma de vida), si no se entiende conjuntamente la pretensión moral de validez universal como parte de la fuerza ilocucionaria. No se trata aquí, entiéndase bien, de que todos los hablantes y destinatarios deban estar fácticamente de acuerdo en la apreciación de las exigencias -y en tal sentido también de la legitimidad moral de las órdenes. Lo esencial para la explicación de la fuerza ilocucionaria es solamente, por cierto, si es necesario comprender al mismo tiempo una pretensión de validez moral -virtualmente justificable como universalmente válida- en tanto componente de la fuerza ilocucionaria de actos de habla tales como exigencias y órdenes, como condición para la comprensión de los mismos en general. Esto es lo que, según mi modo de ver, debe ser aceptado también y precisamente por una teoría del significado. 
Con esto se desprende, a partir del análisis de nuestros tres primeros ejemplos, que la teoría del significado de Searle, en tanto ella recurre a las condiciones de satisfacción de los estados intencionales "in the mind", no puede dar razón de la fuerza ilocucionaria de los actos de habla directivos como un todo. Y la razón de esta falta me parece que reside en el hecho que la articulación y diferenciación lingüística de la fuerza ilocucionaria de los actos de habla puede poner de manifiesto una pretensión de validez intersubjetiva, la cual no se deja reducir a las intenciones prelingüísticas y subjetivas de la voluntad. Solamente el sentido de estas últimas se puede explicitar adecuadamente en los términos de las condiciones de satisfacción.

Este último punto, de la diferencia entre el significado intencional prelingüístico y el significado lingüísticamente institucionalizado, se aclarará plenamente ahora con referencia al cuarto de nuestros ejemplos. Cuando alguien obedece una orden el sentido de las condiciones de satisfacción aparentemente intencionadas, esto puede acontecer de hecho por razones enteramente diferentes a las que toma en consideración alguien que respeta la orden en cuanto tal. Esto no quiere decir sin embargo que el destinatario haya entendido el significado ilocucionario de la orden solamente en el sentido de las condiciones de satisfacción. Todo lo contrario: el destinatario que actúa como oportunista ha entendido muy exactamente la diferencia entre una orden legítima y una ilegítima, pero apoyada en lugar de eso por un considerable potencial de sanción, y ha "aceptado" para sí, en su situación, precisamente ese potencial de sanción como una buena razón para la obediencia de la orden.

¿Qué se sigue de este análisis con referencia a nuestro problema de la explicitación del significado lingüístico en el sentido de la fuerza ilocucionaria de los actos de habla? Me parece que lo que se desprende es la fuerte evidencia de que es preciso abandonar como insuficiente el paradigma de la explicitación del significado en los términos de las condiciones de realización o de las condiciones de satisfacción -y de esta manera también la analogía con el verificacionismo. En lugar de ello, se debe considerar como decisivo para la explicitación del significado lin- 
güístico -según me parece-, el paradigma más comprensivo de las condiciones de validez o de aceptabilidad de los actos de habla, que comprende también las condiciones de verdad de las proposiciones, como condiciones de la posible aceptación de los actos asertóricos.

Es claro que puede darse aquí una, por así decirlo, desagradable circunstancia que podría causarnos problemas. Se trata del hecho aludido, que en la aceptación de actos de habla directivos -como por ej. órdenes, exigencias y especialmente intimaciones-, no se toma en consideración como buena razón evidentemente sólo la validez moral o legal, sino también una amenaza apoyada en la fuerza o la sugestión de una ventaja. Aquí se abre, en el sólo caso de los actos de habla directivos, una dimensión de la comunicación humana, e incluso de la formación de consenso, cuya racionalidad se basa por cierto en la aceptación de buenas razones, pero no de argumentos válidos. Se trata de la dimensión de las negociaciones estratégicas, que tiene que distinguirse de la dimensión del entendimiento fundado en criterios de validez, aunque no se puedan separar realmente en el nivel del mundo de la vida y de la praxis de la comunicación y la interacción cotidiana. Pues bien, los "realistas duros" -como los partidarios de la teoría estratégica de los juegos en la filosofía social-, contraponen a menudo hoy en día esta otra dimensión frente al recurso del "idealismo de la comunicación" a los criterios de validez. Me parece que es preciso hacer frente también a este nuevo desafío. En la siguiente ronda de nuestra discusión del problema de la explicitación del significado ilocucionario intentaremos tener en cuenta en consecuencia al mismo tiempo, tanto los criterios de validez de la razón, como también los criterios estratégicos de racionalidad.

\section{III.- La explicitación pragmático-universal o trascendental del significado ilocucionario de las oraciones o actos de habla en términos de las pretensiones de validez.}

Ante todo quisiera introducir yo ahora un planteo que se conecta, por cierto, con la teoría de los actos de habla, pero que funda, al mismo tiempo, una arquitectónica filosófica de una proyección mucho más 
amplia. De esta manera podrán revertirse una serie de abstracciones metódicas de la filosofía analítica del lenguaje, que han obstaculizado la plena comprensión de la dimensión de validez del logos del lenguaje.

III. 1. Una decisiva ruptura ha sido lograda aquí, según mi modo de ver, por Jürgen Habermas, con su "pragmática universal" o "formal", tal como él la denomina, o "teoría de la competencia comunicativa", la cual ha pasado también como un elemento arquitectónico central, a su "Teoría de la acción comunicativa" (que será citada en adelante como: TAC) (19). Una superación de las "abstractive fallacies", profundamente arraigadas en la tradición filosófica y en la teoría de la ciencia, tiene lugar aquí ante todo mediante la introducción de una tricotomía de las funciones del lenguaje, que se coordina con una correspondiente tricotomía de las pretensiones de validez y de las dimensiones del mundo. Sin embargo, antes de abordar con mayor precisión este planteo, me permito introducir también mi propio planteamiento de una Pragmática trascendental, en muchos puntos emparentada con aquella. De esta manera me será más fácil tratar luego el problema central, tanto para Habermas como para mí, de la tensión entre los criterios de validez y los criterios estratégicos de racionalidad.

Una razón esencial de las dificultades hasta ahora no superadas de la filosofía analítica -y también de la Fenomenología proveniente de Husserl-, para salir adelante con el problema de la relación interna del significado lingüístico y la validez reside, según mi punto de vista, en la limitación abstractiva de la manera de ver a la dimensión de la objetivación del mundo en el sentido de la relación sujeto-objeto. Esto no es por cierto una característica especial de la filosofía más reciente, sino que distingue, como se sabe, a la moderna filosofía desde Descartes $y$, en un sentido que todavía no había alcanzado los extremos de la filosofía de la conciencia, es una característica incluso ya de la precedente tradición ontológico-metafísica. En este mismo sentido ha

(19) Cfer.: J. Habermas, 1976 (ver nota 9, de este cap.), así conı, del mismo autor, theorie des kommunikativen Handelns, Frankfurt a.M., 1981, Bd. 1, cap. I y III. Cfer. también la retrospectiva de Habermas de 1986 . (ver nota 24 , más abajo). 
hablado Heidegger de la preparación del marco de la ciencia y de la técnica moderna en la "ontología de la disponibilidad o de la presencia", y siguiendo a Heidegger ha hablado Derrida del logocentrismo de la filosofía de la "présence".

Ahora bien, la estrechez abstractiva de la manera de ver y de la arquitectónica de la formación del sistema filosófico (y de la teoría de la ciencia) a la perspectiva de la relación sujeto-objeto, se topa con las mayores dificultades precisamente cuando la comprensión lingüística entre los sujetos comienza a ser pensada seriamente como condición de posibilidad, tanto de la constitución del sentido del mundo, como de la resolución de pretensiones de validez por medio del discurso argumentativo. Si se reflexiona sobre esta relación de presuposición necesaria de la intersubjetividad comunicativa por parte del pensar con pretensiones de validez (incluso cuando se trata de un pensar solitario), o para el conocimiento de "algo como algo", entonces no se puede ya tomar como punto de partida, en el sentido del solipsismo metódico de Descartes, y todavía de Husserl, el punto de vista según el cual en principio el sujeto puede considerar todo -incluso, por ej., a los otros en cuanto co-sujetos de la comunidad de comunicación-, como objetos intramundanos de la conciencia de un yo autárquico. No se puede pensar más como si el propio individuo pudiera todavía conocer realmente algo, o por lo menos pensar con pretensión de validez, cuando al hacerlo ha "puesto entre paréntesis" el lenguaje y la comunidad de comunicación que se presuponen para ello, y si ha rebajado a los co-sujetos a meros objetos intramundanos del pensar.

Resulta claro por el contrario que, incluso en el más radical distanciamiento reflexivo del mundo en el sentido de Descartes o Husserl, se presupone siempre todavía el lenguaje como medio de la validez intersubjetiva del sentido, conjuntamente con la intersubjetividad comunicativa. El lenguaje como el medio de los signos expresa aquí, por así decirlo, comparado con la conciencia trascendental, el a priori de la corporalidad intersubjetiva del conocimiento ligado a los signos y del propio pensamiento que, ya desde su punto de partida, depende de los signos. En este último presupuesto se apoya también, según mi 
modo de ver, la posibilidad de pensar adecuadamente la interna relación de significado y validez.

Por esta razón he introducido yo, con la mayor radicalidad posible, el planteo de una transformación pragmático-trascendental o semiótico-trascendental de la filosofía de la conciencia autárquica, construída sobre la base de la relación sujeto-objeto (20). A este planteo pertenece también, como lo he intentado señalar, la tesis que la $d i$ mensión sujeto-cosujeto del entendimiento sobre sentido y validez del lenguaje y de un mundo interpretado lingüísticamente, no puede ser adecuadamente tematizada en el marco de la relación sujeto-objeto del conocimiento del mundo, por cuanto se trata de dos dimensiones diferentes y complementarias. (Por eso, sobre la base de esta situación de complementariedad, yo he intentado también concebir a las ciencias histórico-hermenéuticas como ciencias del entendimiento con los otros).

Hay que tener en cuenta por cierto al mismo tiempo, -y ante todo ya al tematizar la complementariedad trascendental de la relación sujeto-objeto y de la relación sujeto-cosujeto, que nosotros estamos o debemos estar en situación de poder tematizar también las condiciones intersubjetivas de posibilidad de la objetividad. Esto quiere decir, tal como yo lo entiendo, que estamos también en condiciones, en una suerte de objetivación de segundo grado, de hacer objeto de conocimiento y de descripción proposicional con pretensiones de verdad, también aquello que en primera instancia no es objetivable, como por ejemplo, la intersubjetividad comunicativa. Esto no significa sin embargo ninguna objeción contra la tesis de la complementariedad pragmático-trascendental. Por cuanto sabemos también en el nivel de la objetivación de segundo grado, que jamás un sujeto de conciencia solo, en base a sus funciones de conciencia (Kant, Husserl), está capacitado para la tematización de "algo como algo", y que esto solamente es posible bajo los presupuestos comunicativos del entendimiento intersubjetivo en un lenguaje.

(20) Cfer. los trabajos ya citados en nota 3, así como: K.-O. Apel, Transformación de la Filosofia, 2 vol. (1973), trad. cast. Taurus, Madrid, 1985, esp. Tomo I, parte 2. 
(El problema aquí planteado es comparable a mi entender, en sus aspectos esenciales, con el problema con que se ve confrontado el otro intento de trascender la relación sujeto-objeto del "Gestell", o del logos de la presencia, que está hoy en el centro de la discusión. Me refiero al intento, de proveniencia heideggeriana, de pensar como posible una trascendencia de lo que hasta aquí se ha llamado filosofía y ciencia, sobre la base de la diferencia óntico-ontológica entre los entes objetivables (incluido el concepto abstracto del ser) y el ser en su temporalidad no objetivable. También este intento se enfrenta a mi entender con la ineludible tarea de justificar cómo es posible para él hacer enunciados con pretensiones de validez -por ejemplo con la pretensión de verdad proposicional, sobre el acontecer temporal de la diferencia que se manifiesta y se oculta).

Volvamos ahora al problema de la posibilidad de trascender la "abstractive fallacy" que está en la base de la absolutización de la relación sujeto-objeto mediante la introducción de la dimensión de la intersubjetividad comunicativa, y por lo tanto del entendimiento con los otros sobre el sentido y la validez del lenguaje y del mundo lingüísticamente interpretado, que está presupuesto en el pensar y en el conocimiento en general.

Jürgen Habermas ha sostenido asimismo desde hace décadas el planteo que acabamos de explicar en el sentido de mi tesis sobre la complementariedad pragmático-trascendental -o más precisamente: un planteo que se corresponde con éste, como lo mostraremos enseguida. Pero él lo ha diferenciado todavía más en su pragmática universal o formal, en el sentido de una tricotomía. Es decir que ha introducido del lado de la comunicación entre el sujeto y el co-sujeto una nueva diferenciación: entre la apelación comunicativa, o la "pretensión" planteada a los destinatarios, y la manifestación del mundo interior subjetivo del hablante. De esta manera ha podido fundar Habermas una arquitectónica filosófica que permite, desde el punto de vista de las relaciones del lenguaje y el mundo, y desde el punto de vista de las relaciones de significado y validez, las siguientes diferenciaciones: 
* primero, en conexión con Karl Bühler, la diferenciación de tres funciones del lenguaje: la función expositiva, referida a las proposiciones, la función expresiva y la función apelativa;

* en segundo lugar, la diferenciación entre tres dimensiones del mundo:

1. Mundo de los objetos de referencia, o de los estados de cosas que se describen,

2. Mundo social de la interacción y la comunicación regulada por normas,

3. Mundo interior, subjetivo;

* en tercer lugar, como diferenciación de la pretensión de sentido o comprensibilidad de los actos de habla (que sirve normalmente de mediación en la "acción comunicativa" de la interacción y coordinación social): las tres pretensiones de validez universales específicas (es decir, en el contexto de nuestro problema actual, tres dimensiones de la posible validez a la luz de la cual se puede entender el significado ilocucionario o la fuerza de los actos de habla):

1. La pretensión de verdad referida al mundo objetivo, cuyos portadores son las proposiciones afirmadas de los actos de habla constatativos o asertóricos;

2. La pretensión de rectitud de los actos de habla en cuanto actos comunicativos, con referencia a las normas (jurídicas o morales) del mundo social, los cuales plantean una exigencia frente a los destinatarios;

3. La pretensión de veracidad o de sinceridad de los actos de habla en cuanto automanifestación expresiva que exponen algo del mundo interior, subjetivo del hablante.

Además, en este contexto ha planteado Habermas la importante distinción entre la comunicación del mundo de la vida y el discurso argumentativo "descargado de los contextos de acción". En el nivel de la comunicación y la interacción del mundo de la vida el entendimiento tiene lugar, según Habermas, al servicio de la coordinación social de las acciones; y esta coordinación tiene lugar, normalmente sobre la base de la "fuerza social vinculante", que tienen las "preten- 
siones de validez" en la medida en que no solamente son entendidas sino también aceptadas. En el nivel del discurso argumentativo "descargado de los contextos de acción", por otro lado, la comunicación e interacción del mundo de la vida es objeto de análisis reflexivo y crítico. Esto quiere decir que las pretensiones de la validez de los actos de comunicación que han sido entendidas, pero no aceptadas, pueden ser rescatadas o rechazadas mediante argumentos.

¿Qué rendimiento presenta ahora la arquitectónica esbozada por Habermas para la respuesta a la cuestión que venimos planteando: de la explicación del significado ilocucionario, por una parte, y de los criterios estratégicos de racionalidad, por otra parte?

III. 2. Antes de ensayar una respuesta a esta pregunta, quiero intercalar todavía una observación sobre mi posición con respecto a la "arquitectónica" habermasiana. Yo he encontrado plausible esta arquitectónica en su tricotomía, y ni bien tomé conocimiento de ella he intentado integrarla en mi programa pragmático-trascendental. Al trabajar en esto me topé ciertamente con alguna dificultad, que quisiera interpretar ahora sin embargo como una diferencia de principio.

Yo no puedo comprender y valorar exactamente de la misma manera que Habermas la comunicación e interacción del mundo de la vida por un lado, y por otro lado el discurso argumentativo en su significado para la fundamentación de la resolución racional de las tres diferentes pretensiones de validez. Más precisamente: yo comparto por cierto la opinión que el discurso descargado de los contextos de acción tiene la función de resolver las pretensiones de validez problematizadas en el mundo de la vida a través de argumentos que sean aptos para obtener consenso, y solamente por este medio. Pero sin embargo me veo obligado a evaluar de manera diferente que Habermas, esto es, más dramáticamente, el problema de la fundamentación que en esta situación se plantea. Esto se conecta naturalmente con el hecho que yo me mantengo aferrado al programa de una transformación de la filosofía trascendental -y en este contexto sostengo incluso la necesidad de una fundamentación última 
reflexiva que va más allá de Kant (21). En el contexto de la problemática que ahora tenemos entre manos, me voy a limitar, sin embargo, a ilustrar la diferencia existente entre Habermas y yo con respecto a la cuestión planteada de la explicitación del significado ilocucionario.

Ante todo quisiera destacar una vez más el gran logro de la concepción habermasiana que reside, a mi modo de ver, en la posibilidad de transgredir radicalmente la limitación abstractiva de la explicitación que la filosofía analítica (o más precisamente: "la semántica formal") había impuesto sobre el significado lingüístico en los términos de las condiciones de verdad, y en analogía con esto, de las condiciones de realización o de satisfacción, superando las mismas en el sentido de una explicitación en los términos de las condiciones de validez, o de aceptabilidad. Este progreso se hace posible mediante tres pasos del pensamiento de Habermas que se articulan del modo siguiente:

1. En primer lugar, la concepción habermasiana de las tres referencias del lenguaje al mundo trasciende en principio, y de manera radical, la tematización de las relaciones del lenguaje y el mundo limitada a la verdad cognoscitiva en el sentido de la relación sujetoobjeto, y con esto a la correspondencia de oraciones proposicionales y estado de cosas. De esta manera -es decir: por medio de la consideración de la referencia del lenguaje al mundo social determinado normativamente, y al mundo interior subjetivo, se hace posible por primera vez ahora comprender con su peculiaridad el específico significado, esto es, la "fuerza ilocucionaria" de los actos de habla no constatativos o no asertóricos.

Es posible así, por ejemplo, darse cuenta que la comprensión y la eventual aceptación de los actos de habla directivos, que hemos

(21) Cfer.: K.-O. Apel, "Das Problem der philosophischen Letzebegründung in Lichte einer transzendentalen Sprachpragmatik: Versuch einer Metakritik des "Kritischen Rationalismus", en B. B. Kanitscheider (edit.), Sprache und Erkenntnis, Festschrift f. G. Frey, Insbruck, 1976, p. 55-82, (hay trad. cast. en Dianoia, XXI, México, 1975); del mismo autor: "Fallibilismus, Konsenstheorie der Wahrheit und Letzebegründung", en W. Kuhlmann (edt), Philosophie und Begründung, Frankfort, 1987 (hay trad. cast. en K.O.Apel, Teoría de la verdad y ética del discurso, Paidós, Barcelona, 1991), cfer. también W. Kuhlmann, Reflexive Letzebegründung, Untersuchungen zur Transzendentalpragmatik, Freibo'rrg/München, 1985. 
discutido a manera de ejemplo, está codeterminada de manera esencial por la comprensión de su pretensión de validez normativa y de las condiciones de validez presupuestas en eso. Así por ejemplo en el caso de las ordenes, pedidos, exigencias, etc.

Más allá de esto, la tricotomía habermasiana posibilita también por primera vez reconocer en su peculiaridad la pretensión de validez específica que determina la "fuerza ilocucionaria" de los actos de habla expresivos, es decir, por ejemplo, de las confesiones y aseveraciones. Dicha tricotomía permite también coordinar a este tipo de actos de habla un peculiar "mundo de referencia" que aparece como específicamente diferente de la referencia cognitiva al mundo objetivo, tanto como de la referencia apelativa al mundo social.

(Se hace posible comprender ahora por ejemplo de manera crítico reconstructiva un punto central de la concepción de Dilthey del sentido metafísico de la validez o de la verdad. A diferencia del neopositivismo era Dilthey de la opinión que los sitemas metafísicos, de la misma manera que las grandes obras de arte, pueden considerarse todavía como plenos de sentido, e incluso como verdaderos en un sentido profundo, aunque su pretensión de valdez, a la luz de las condiciones de verdad comprendidas al modo del conocimiento científico -o sea en el sentido del verificacionismo aparezca en principio como imposible de resolver o de rescartar. Su sentido y su verdad reside para Dilthey en el hecho que ellos presentan la expresión auténtica de diferentes aspectos de la polifacética realidad de la vida y de la experiencia humana (22). Rudolf Carnap, que conoció esta doctrina como discípulo de Hermann Nohls, ha sacado de ella sin embargo, abiertamente, la consecuencia que entonces la metafísica armonística de Leibnitz tendría su mejor expresión a través de la música de Mozart, y la metafísica dualista de Kant a través de la música de Beethoven

(22) Cfer.: W. Dilthey, Ges. Schriften, Bd. VIII, Weltanschauugslehere, Abhandlungen zur Philosophie der Philosophie, Hrsgg. v.: B. Goethuysen, Leipzig/Berlin 1931 , S. 3-9, 68-87, 95-118. 
(23). ¿En qué reside entonces la visión de Dilthey? No se puede fundar, sobre la base de esa visión, como Dilthey sugería, una reducción de la filosofía a las ciencias del espíritu en el sentido de la mera reinterpretación de la autenticidad de las expresiones de la vida. Esto se hace enseguida evidente si se tiene en claro que las propias concepciones de Dilthey sobre la esencia expresiva de la metafísica y el arte auténticos, no querían ser entendidas como mera expresión auténtica de un aspecto de la vida, sino de alguna manera como comprensión filosófico-científica universalmente válida de la esencia de la realidad histórico-social).

Ahora bien, este problema se puede esclarecer en gran medida, según mi modo de ver, a la luz de la tricotomía habermasiana de las pretensiones de validez y su posible resolución. Para lo cual se debe prescindir sin embargo del hecho que tampoco Habermas está dispuesto en última instancia, coincidiendo en este punto con Dilthey, a reconocer una diferencia metodológicamente relevante entre las pretensiones de validez universal de la filosofía -por ejemplo de la propia-, y las pretensiones de validez de las ciencias sociales reconstructivas (24).

(23) R. Carnap, "Überwindung der Metaphysik durch Logische Analyse der Sprache", en "Erkenntnis" 2., 1931, S. 219-241, hier S. 240. Wiederabgedruckt in H.Schleicher (Hrsg), Logischer Empirismus der Wiener Kreis, München, 1975, S. 149-173, hier S. 170.

(24) Ver J. Habermas, "Was Heisst Universalpragmatik?", op. cit., cfer. nota 9 y su respuesta a Kuhlmann en a. Honnet/H. Jonas (Edit.), Kommunikatives Handeln, Frankfurt a:M., 1986, 349 ss. Sobre esto: W. Kuhlmann, "Philosophie und rekonstruktive Wissenschaft. Bemerkungen zu J. Habermas Theorie des kommu. nikativen Handelns, en "Zeitschrift f. Philosophische Forschung", 40, 1986, pp. 224-234; así como K.-O. Apel, "Fallibilismus, Konsenstheorie der Wahrheit und Letzebegründung", op. cit. cfer. nota 21 . En la citada confrontación con sus críticos, que lo acusan de idealismo encubierto en su descripción sociológica de las relaciones de interacción y comunicación del mundo de la vida, se ve forzado el propio Habernas por supuesto reiteradamente a recurrir a la diferencia entre los planteamientos filosólfico y sociológico de las cuestiones y a destacar en especial la diferencia entre el concepto pragmático formal y el concepto sociológico del "mundo de la vida". Se ha visto precisado a argumentar de hecho como si la "Teoría de la Acción comunicativa" pudiera presuponer para él mismo una fundamentación pragmático trascendetal. De esto no he dudado yo nunca por cierto. 
Sobre la tercera dimensión de las pretensiones de validez ilocucionaria quisiera observar aquí solamente que, como Habermas mismo también lo sabe, la conexión interna entre la pretensión de veracidad de los actos de habla y la pretensión de autenticidad del arte expresivo no es suficiente para fundar por ejemplo una estética. De todos modos me parece que se ha puesto con esto efectivamente en descubierto una condición necesaria de todo arte genuino, y un criterio de validez ineludible de la racionalidad de la crítica de arte.

2. Estrechamente ligado con la función esclarecedora de la tricotomía de los mundos de referencia y de las pretensiones de validez que acabamos de caracterizar, hay todavía un segundo paso del pensamiento de Habermas que es constitutivo de su teoría del discurso, y que me parece más importante aún para una comprensión más profunda de la conexión interna entre significado ilocucionario o fuerza del habla y validez. El concepto de verdad no puede, o no debería comprenderse ya tampoco, en una perspectiva lingüístico pragmática, como lo he señalado precedentemente, exclusiva o primariamente en el sentido de la dimensión de las condiciones de realización, sino más bien como un caso especial de la validez intersubjetiva, es decir, por analogía con la posibilidad de resolución argumentativa de pretensiones de validez.

Siguiendo a Habermas en este paso de su pensamiento, se llega a una teoría del discurso, en la cual el concepto de verdad solamente puede explicitarse ya en la medida en que se ticne en cuenta la presuposición recíproca de los conceptos de:

* verdad,

* pretensión de verdad (de los actos de habla asertóricos) y

* resolución de las pretensiones de verdad mediante el aporte de buenas razones en el discurso argumentativo.

Se muestra ahora que el notable predicado "...es verdadero", el cual es atribuído a las oraciones proposicionales en el nivel metalingüístico, y que no corresponde a ninguna propiedad de objetos intramundanos, solamente puede ser comprendido bajo una condición: es 
preciso retornar a las pretensiones de verdad implicadas en la fuerza ilocucionaria de los actos de habla (mediante un acto que yo llamaría de reflexión trascendental). Esto quiere decir que la abstracta problemática lógico-semántica de la correspondencia de las oraciones proposicionales y los estados de cosas existentes, se debe desplazar, por así decirlo, al contexto del discurso. Solamente con esto queda definitivamente cancelada la "abstractive fallacy" de la semántica lógica (que a través de Tarski y Carnap se remonta a Frege y Bolzano).

Se puede mostrar además que la pretensión de verdad no puede ser planteada explícitamente por nosotros hombres sin que se exponga también, al mismo tiempo, implícitamente -en el nivel interno correspondiente del discurso argumentativo- una pretensión de veracidad y una pretensión de rectitud moralmente relevante para los actos asertóricos en cuanto actos comunicativos. Ahora bien, la pretensión de rectitud de un acto asertórico en cuanto acto comunicativo, como así también la pertinente pretensión de veracidad (la cual no puede ser resuelta ya mediante argumentos, sino solamente a través de la praxis), se refieren a criterios de validez normativos ideales, criterios que uno debe haber reconocido ya siempre como universalmente válidos. No se puede plantear una pretensión de verdad, en el marco de una argumentación en serio, y sostenerla en principio como apta para obtener consenso, si uno no ha reconocido al mismo tiempo, al realizar dicho acto, las normas morales que son decisivas para una comunidad ideal de comunicación (la cual ha sido anticipada contrafácticamente como existente).

(Sobre este pensamiento he fundado yo el concepto de una fundamentación trascendental última de la filosofía teórica y de la ética, que sigo sosteniendo siempre como válido. Es claro que la fundamentación última solamente se puede llevar a cabo mediante una reflexión estricta sobre las presuposiciones de un argumentar filosófico en acto. De tal manera que, con respecto a todo intento de impugnación o ya de formulación de dudas, se pueda mostrar que ál se tiene que enredar en una autocontradicción performativa. No se puede reemplazar esta fundamentación última pragmático-trascendental de las condiciones ideales de validez, -es decir, esta argumentación estrictamente reflexiva-, mediante el recurso al trasfondo de certezas fácticamente irreba- 
sabies del "mundo de la vida" -o más precisamente: de los mundos de la vida que corresponden a las diferentes "formas de vida" (Wittgenstein)- como está hoy tan en boga. Sobre este punto volveré todavía bajo distintos aspectos).

Con esto es suficiente sobre los resultados de la ampliación pragmática universal, que según mi modo de ver debería interpretarse también en un nivel pragmático trascendental, de los presupuestos de contexto para la posible explicitación del significado ilocucionario a la luz de las condiciones' de validez en cuanto condiciones de aceptabilidad discursiva. Pero ahora debemos pasar a la circunstancia calificada por mí como desagradable, que en la praxis de la comunicación y la interacción del mundo de la vida operan como buenas razones para la aceptación o no aceptación de los actos de habla no solamente los criterios de validez sino también criterios estratégicos de racionalidad. ¿Qué respuesta se puede dar sobre esto a los argumentos que los llamados realistas duros y los empiristas, atendiendo precisamente a esta circunstancia, plantean contra lo que ellos llaman el "idealismo de la comunicación"?

III. 3. En este lugar sale a luz ahora una diferencia entre Habermas y yo, que ya había sido aludida más arriba, pero que cobra una forma quizás inesperada para muchos, por cuanto yo debo dar la razón en primer lugar una vez a los así llamados realistas y empiristas contra Habermas en un importante punto.

Resulta a mi modo de ver sencillamente falso decir que, en el nivel de la praxis de la comunicación y la interacción del mundo de la vida, el entendimiento y la coordinación de las acciones sociales tiene lugar normalmente sobre la base de la "fuerza social vinculante" de las pretensiones de validez aceptadas -y por lo tanto a la luz de criterios de validez universalmente reconocidos, como son las normas jurídicas o morales. En este enunciado reside una idealización que, -si no se la reflexiona y fundamenta como tal, sino que se la presenta como resultado de una descripción "quasi" fenomenológica-, desemboca en una "idealistic fallacy". Es así por cuanto con ello se ignora que en el nivel de la interacción del mundo de la vida la "coordinación de las acciones" -e incluso la formación del 
consenso lingüísticamente mediado que posibilita tal coordinación-, ocurre por lo menos con tanta frecuencia, o en la misma medida, sobre la base de negociaciones abiertamente estratégicas, o de sugestiones comunicativas encubiertamente estratégicas. De tal manera que los destinatarios de actos de habla no los aceptan sobre la base de la fuerza social vinculatoria de sus implícitas pretensiones de validez, sino por motivaciones oportunistas. (Más correcto sería decir incluso, según mi opinión, que la coordinación de las acciones en las circunstancias existentes solamente puede funcionar a la manera de un compromiso de mediación -que es por supuesto modificable-, entre las formas diferenciables como tipos ideales en cierto modo contrapuestos de la motivación racional de la formación fáctica de consenso (25).

Ahora bien, Habermas no ha pasado enteramente por alto por cierto los hechos aquí aludidos. En su "Teoría de la Acción comunicativa", sin embargo, sorprendentemente ha dejado casi enteramente de lado la función de las negociaciones abiertamente estratégicas, y consecuentemente también de los actos de habla abiertamente estratégicos (26). Pero ha analizado en cambio de manera muy penetrante

(25) En este lugar prescindo yo enteramente del hecho que, también la "fuerza social vinculatoria" de las pretensiones de validez en el mundo de la vida -aún en el caso que ellas sean evaluadas subjetivamente como universalmente válidas -se apoya en el "trasfondo" de presupuestos fácticos, (históricos), de las diferentes formas de vida-, sobre presupuestos de contexto por lo tanto, los cuales son ellos mismos ya el resultado de compromisos históricos entre pretensiones de validez y pretensiones de poder.

(26) No se puede decir que haya pasado esto totalmente por alto, por cuanto ha tenido en vista una clase especial de actos de habla como los imperativos abiertamente estratégicos en el sentido, por ejemplo, de la expresión: "arriba las manos!". Pero sin embargo, este tratamiento de la cuestión, como restringida a una clase especial de actos de habla, me parece que encubre nás bien la efectiva función de la "formación de consenso" por medio de negociaciones más o menos abiertamente estratégicas, aunque enteramente "civilizadas" en sus procedimientos. En su respuesta a los críticos en el libro Acción Comunicativa, editado por $\mathrm{A}$. Honneth (cfr. más arriba, nota 24) muestra Habermas que lo que aquí se advierte desde un punto de vista realista, o incluso empirista, lo sabe él por cierto, y también lo ha tenido en cuenta, aunque en otro contexto (cfr. op. cit., p. 361 ss.). Pero sin embargo con esto no se logra eliminar, según mi modo de ver, la dificultad de principio que aquí vamos a tematizar, la cual surge fundamentalmente de la arquitectónica del planteo de la TAC. 
la función de los actos de habla encubiertamente estratégicos. Ahora bien, si mi interpretación es correcta, con estc notable desequilibrio se conecta precisamente una falacia idealista de apreciación de las condiciones del mundo de la vida. Veamos en qué medida es así.

En el 1er. Tomo de su TAC J. Habermas ha presentado una fundamentación convincente de porqué las comunicaciones encubiertamente estratégicas no pueden representar el paradigma de la comunicación humana. La razón de ello es simplemente la siguiente: quien intenta alcanzar sus fines -por ejemplo el logro de determinadas metas políticas o económicas- con respecto a los destinatarios de una aloclición, mediante la subrepción encubiertamente estratégica del efecto perlocucionario de la misma, tiene que despertar en los oyentes a pesar de ello, o más bien justamente por eso, la impresión de darles la chance, en el nivel de una comunicación lingüística oficialmente abierta a la comprensión, de poder juzgar la fuerza ilocucionaria del habla como orientada por pretensiones de validez. Expresado de manera más simple: quien intenta persuadir (o engañar) exitosamente a alguien mediante procedimientos retóricos (überreden), tiene que despertar en el oyente la impresión de que desea convencerlo (überzeugen) con argumentos. Este es el secreto de la ambigüedad y la ambivalencia, que ha durado más de 2000 años, de la tradición retórica occidental. (Esto queda testificado por la notoria anfibología de todos los términos derivados de persuadere, persuasio o persuasivus) (27).

(27) He podido comprobar esta anfibología con motivo de las traducciones en inglés, francés e italiano (al observar la versión de "überzeugen" (convencer) por derivados de "persuadere" (überreden). Al sostener una vez en Chicago el concepto de "la resoluciónh argumentativa de pretensiones de validez", que comparto con Habermas, después de la conferencia alguien me opuso, desde una posición cercana a Rorty, la siguiente recomendación: "You Should not have validity-claims; you should jus be persuasive!". Para esclarecer el trasfondo de este malentendido se requeriría a mi entender una reconstrucción crítica de la historia de la retórica desde el punto de vista de una teoría de los actos de habla interpretada de modo pragmátion- trascendental. Ella debería comenzar con el uso platónioo de $\pi \varepsilon \imath \theta \omega$ en Gorgias y Fedro. En efecto, de lo que se trataba ya en Platón no era en rigor de la diferencia estructural entre "überzeugen e überreden"; sino más bien de legitimar también la persuación (con medios retóricos) a partir del saber de las ideas que los filósofos poseen. 
Si esto es correcto, es decir: si el propio sujeto de los actos de habla encubiertamente estratégicos debe simular un uso no estratégico del lenguaje, entonces se reconoce ya con ello implícitamente la primacía normativa de la fuerza ilocucionaria del habla que se basa en pretensiones de validez. Y de esta manera queda justificado el planteamiento de la siguiente tesis: ya en el nivel de la praxis comunicativa del mundo de la vida se reconoce, por lo menos de manera implícita, que la comunicación encubiertamente estratégica depende parasitariamente de aquella otra forma de comunicación que recibe su fuerza social vinculante del implícito recurso a pretensiones de validez susceptibles de justificación racional. Este es el punto de vista central de Habermas en este asunto, y en él se apoya también evidentemente su tesis de la normalidad del carácter no estratégico de la praxis comunicativa en el mundo de la vida.

Pero hay dos razones por las cuales esta tesis aparece como injustificada, o por lo menos ambigua:

1. En primer lugar, el argumento de Habermas no certifica la normalidad fáctica del uso no estratégico del lenguaje en el mundo de la vida, es decir, que este sea de hecho el uso normal o predominante del lenguaje. Lo que muestra en realidad es solamente el primado normativo del mismo, que es reconocido incluso ya en el nivel de la praxis del mundo de la vida. Volveré nuevamente más adelante sobre esta diferencia que el propio Habermas ha reconocido en muchos lugares.

2. En segundo lugar, tampoco ha demostrado Habermas en absoluto con su argumento que se haya reconocido también necesariamente en el nivel de la praxis cotidiana del mundo de la vida el primado normativo de las pretensiones de validez -y con ello el primado de la racionalidad de la formación de consenso basada en criterios de validez-, con respecto a la racionalidad abiertamente estratégica, apoyada en relaciones de poder.Que esto no es verdadero en sentido de la normalidad fáctica se demuestra ya por el hecho del papel que juegan las negociaciones más o menos abiertamente estratégicas en la formación de los consensos política y económicamente relevantes que 
son fácticamente efectivos (28). Pero todavía más: mediante el recurso a la praxis del mundo de la vida no puede ser demostrado por principio que sea reconocido en general el primado normativo de la formación no estratégica de consenso. Quien confronta a sus interlocutores con amenazas $\mathrm{u}$ ofertas de beneficios en un proceso de negociación abiertamente estratégica, al hacer esto está reconociendo por cierto de hecho el primado del "habla orientada al entendimiento", puesto que deja enteramente de lado el uso encubiertamente estratégico del lenguaje -a diferencia de quien intenta persuadir simulando que trata de convencer. Pero sin embargo, no se reconoce in actu con esto de ninguna manera el primado normativo de la comunicación no estratégica. (Si el sujeto que actúa de la manera aludida estuviera dispuesto a rendir cuentas de su actitud, podría remitirse él a Nietzsche o a Foulcault para explicar que: "todo uso del lenguaje despliega una práctica de poder. Las buenas razones que son capaces de mover a los destinatarios de los actos de habla a la aceptación de las "ofertas" transmitidas por medio del lenguaje, son siempre, en última instancia, consideraciones del orden de la racionalidad estratégica". Esta explicación recibiría inmediatamente el aplauso de los representantes de la teoría estratégica de los juegos!).

Existe por lo tanto una diferencia fundamental -en el nivel de la praxis del mundo de la vida- entre la posición de quiénes se comunican de manera abiertamente estratégica y la de quiénes hacen un uso encubiertamente estratégico del lenguaje y reconocen, por lo tanto, justamente con eso, el primado de la formación no estratégica de consenso. Este es el importante punto de vista que Habermas pasa por alto según mi modo de ver. Ello se comprueba cuando, en su confrontación con los críticos de la TAC (29), intenta salir airoso frente al hecho del uso abiertamente estratégico del lenguaje mediante el

(28) Un ejemplo especialmente característico de la mezcla de las categorías en la realidad del mundo de la vida lo ofrece la discusión actual en los Estados Unidos sobre la cuestión si se debe institucionalizar en el orden jurídico la práctica del "plea-bargaining".

(29) Cfr. más abajo, nota 26. 
mismo argumento que ha esgrimido, exitosamente por cierto, contra el uso encubiertamente estratégico, a saber: el ya mencionado argumento del parasitismo. Pero resulta que este argumento solamente puede funcionar cuando uno puede hacerle comprobar al defensor de la racionalidad estratégica de la comunicación que él también ha reconocido ya el primado normativo de las pretensiones de validez y de su resolución no estratégica a través de criterios de validez. Ahora bien, este procedimiento no puede aplicarse precisamente a quien, en procesos como las negociaciones, hace jugar pura y simplemente "argumentos" de poder, y a quien, frente a la apelación del adversario al derecho que le asiste (ya sea en el sentido de la moralidad o de la legalidad), declara que no reconoce por principio ningún punto de vista de derecho que no se subordine en última instancia -"como es natural", por así decirlo- al punto de vista del poder. (Este fue el criterio sostenido por los atenienses -que en este sentido eran ya "ilustrados"-, en sus tristemente famosas negociaciones con los medos (30), y fue también el punto de vista reiterada y abiertamente confesado del darwinismo social de Hitler).

Puede verse que lo que aquí se pone en juego es, en rigor, la posibilidad de una fundamentación última racional de la ética. Pues justamente en esto consiste la pregunta decisiva de una fundamentación postconvencional de la ética: ¡es posible movilizar un argumento racional contra el uso meramente estratégico de los otros, es decir, en el sentido de Kant: "como meros medios"?. Como se sabe, la posibilidad de un argumento racional contra esto fue negada por Horkheimer y Adorno en la Dialéctica de la Ilustración mediante el recurso a Nietzsche y a de Sade (31). Y los postmodernistas naturalmente están de acuerdo con ellos.

No he expuesto la crítica a Habermas (naturalmente!) para abandonarlo a su propia suerte. Según mi modo de ver, sigue siendo co-

(30) Tucídides, 5, 84-116.

(31) Cfer. Dialektik der Aufklärung, Frunkfurt a.M. 1971, p. 78. ss. 
rrecto que no se puede demostrar el reconocimiento del primado normativo de la comunicación y de la formación de consenso no estratégicos mediante la reconstrucción empírica comprensiva de la praxis del mundo de la vida. (No se debería idealizar el mundo de la vida, como lo hace Habermas en este momento, cuando piensa que se debe dudar de la posibilidad de una fundamentación filosófica última de la ética. A uno le cuesta creer a sus propios ojos cuando lee -y no en alguien como Rorty, sino en el propio Habermas-, que "las intuiciones morales de la vida cotidiana", "no requieren el esclarecimiento de la ética filosófica", o que "la ética filosófica (posee) en todo caso una función esclarecedora frente a las confusiones que ella misma ha ocasionado en las conciencias ilustradas" (32). ¿Cómo se pueden poner de acuerdo esas más que infelices formulaciones (que han irritado a muchos de los conocedores de Habermas) con la concepción sostenida por el propio Habermas que las épocas de ilustración filosófica introducen el pasaje de la eticidad convencional a la moralidad postconvencional? ¿Habría que entender entonces los procesos históricos como el de la ilustración socrática en Grecia y finalmente la ilustración moderna del S. XVIII como meros devaneos y juegos de lenguaje de los filósofos, que no respondieron a ninguna motivación real en el sentido de una situación de crisis sociocultural? ¿Y no tendría nada que ver tampoco -para nosotros hoy!- con los logros filosóficos de las épocas de ilustración, el posible pasaje de la comunicación irreflexiva al discurso argumentativo en los casos de diferencias de opiniones y conflictos? Tales puntos de vista contradicen evidentemente todo lo que Habermas mismo ha escrito. (Si fuera necesario sería preciso defender aquí a Habermas contra Habermas).

Pero volvamos ahora a nuestro problema: ¿cómo debe demostrarse entonces el primado de la comunicación no estratégica, si el propio Habermas no lo ha logrado con referencia al uso abiertamente estratégico del lenguaje? Lo que no es posible por medio de la reconstrucción de la praxis del mundo de la vida -de sus pretensiones de validez y del tras-

(32) J. Habermas, Moralbewußtsein und kommunikatives Handeln, Frankfurt, a.M. 1983, p. 108. 
fondo de sus certezas convencionales-, esto se torna muy bien posible si uno reflexiona, en el nivel del discurso argumentativo sobre pretensiones de validez problematizadas, acerca de las presuposiciones que aquí han reconocido implícitamente de manera necesaria todos los participantes de la comunicación. ¿En qué medida es ahora fundamentalmente diferente la situación del problema?

Yo estoy de acuerdo con Habermas en la opinión de que el discurso argumentativo (que según mi modo de ver es un logro de la filosofía, y que condiciona también la interdependencia inescindible de filosofía y ciencias particulares) representa, por así decirlo, la forma reflexiva de la comunicación humana. Esto quiere decir lo siguiente: siempre que los hombres, en el caso de una diferencia de opiniones, o de un conflicto práctico, quieran saber quién tiene razón, es decir: siempre que quieran saber si sus pretensiones de validez son rescatables como intersubjetivamente válidas, entonces se les presenta el pasaje al discurso argumentativo como la única alternativa desde ya ineludible frente a la lucha abierta o a las negociaciones estratégicas, y como la forma irrebasable de la racionalidad, incorporada ya en el propio lenguaje. Pero este es el paso que se rehúsa a dar el contrincante que prácticamente se posiciona en el punto de vista del poder. $Y$ es por eso que Habermas nada puede lograr contra él. No podrá lograr nada frente a él, podemos decir trivialmente, mientras el contrincante, por su lado, no quiere ingresar en el terreno del discurso argumentativo y, por lo tanto, no tiene de hecho ni siquiera la posibilidad de comenzar a argumentar. La situación es, en cambio, enteramente diferente, cuando el contrincante quiere argumentar en serio (aunque fuere, con Nietzsche, en defensa del punto de vista del poder, o como escéptico radical). Por cuanto a partir de ese momento, como habrá de mostrarse, el contrincante debe reconocer performativamente de manera necesaria ciertas normas del discurso.

Es importante destacar en este contexto que nosotros en cuanto filósofos tenemos razones para presuponer que todo posible participante en el discurso -incluso los escépticos radicales y los relativistas- ha pisado ya el terreno en el que se apoya el discurso argumentativo, por ejemplo cuan- 
do se trata de responder a la cuestión si es posible o no el recurso a un argumento racional contra el tratamiento meramente estratégico de los otros. El filósofo no se encuentra por cierto comprometido a responder esta pregunta a quien en absoluto no se la plantea, sino que rehusa convencer mediante argumentos de la utilidad del sometimiento bajo sus pretensiones de poder y niega ya la existencia misma de una igualdad básica de derechos como la que presupone el discurso (33). Este último pertenece más bien simplemente a aquella realidad del mundo de la vida sobre la cual uno puede hablar (en el plano del discurso), y sobre la cual no debería hacerse uno ninguna ilusión.

Pero si nosotros presuponemos ahora justificadamente que nuestro interlocutor en el discurso comparte con nosotros el mismo problema planteado, entonces -mediante la reflexión trascendental sobre las presuposiciones incuestionables del discurso- podemos llegar conjuntamente al convencimiento que nosotros hemos reconocido ya necesariamente que por principio no podríamos resolver nuestro problema mediante negociaciones estratégicas.

Ahora, en el nivel del discurso, podemos entender fácilmente que la aseveración de que todo uso del lenguaje, -también la argumentaciónno es más que una práctica de poder, desemboca en una autocontradicción performativa; una autocontradicción que suprime el sentido del discurso argumentativo. Expresado de manera positiva: podemos mostrar ahora incluso que la tesis de Habermas de que aún el uso abiertamente estratégico del lenguaje -como por ejemplo el recurso cínico a las amenazas u ofertas de beneficios-, es parasitario en relación con el uso no estratégico, orientado al entendimiento, es una tesis que se apoya en una intuición correcta. Por cuanto en relación con la orientación im-

(33) Habermas sostiene esto abiertamente -con muchos otros-como un argumento contra la posibilidad de una fundamentación última. Cfr. op. cit., en nota anterior, p. 109. Yo tampoco dejaría de admitir naturalmente que el rechazo del discurso practicado de manera efectiva (no en cambio el pretendido argumento de quien en el marco del propio discurso dice: ¿Y si yo no acepto ahora el discurso?), constituye un serio problema real para todos aquellos que estan dispuestos a resolver discursivamente sus diferencias de opiniones y conflictos. Pero este sería un problema estratégico, o pedagógico, y eventualmente un problema terapéutico. No puede representar en cambio ninguna aporía en el discurso filosófico de la fundamentación. 
plícita de todo argumentante a la formación de consenso, el uso abiertamente estratégico del lenguaje es efectivamente parasitario.

¿Ahora bien, cómo se muestra esto en el nivel del discurso argumentativo? Ensayemos reconstruir ahora de manera más precisa el pasaje del discurso: las situaciones de comunicación no ofrecen de manera inmediata -como ya hemos notado-, ninguna oportunidad para la aplicación del argumento del parasitismo. Puesto que quien se pone abiertamente en una posición de poder, no necesita persuadir a sus adversarios a través de la simulación de querer convencerlos mediante argumentos. Si es que él argumenta, puede intentar convencerlos en todo caso que hay buenas razones para ellos, en el sentido de sus propios intereses, para aceptar lo que plantean sus actos de habla, por ejemplo una exigencia. Pero en la medida en que él intenta esto realmente (es decir: en la medida en que se embarca en la empresa de lograr convencimientos mediante argumentaciones) debe admitir ya entonces que ha reconocido a sus interlocutores (entablando con ellos una relación que no es ya mera relación de poder). Se trata aquí de verdaderos interlocutores con respecto al reconocimiento de una auténtica pretensión de validez, aunque la cuestión de validez esté restringida en este caso a la pretensión de verdad con respecto a la superioridad fáctica de la posición de poder del hablante. Con esto empero, en la medida en que el hablante efectivamente argumenta para obtener el reconocimiento de su pretensión de poder, ha reconocido también que el uso del lenguaje abiertamente estratégico es básicamente "parasitario", con respecto al "uso orientado al entendimiento", que él ha revelado explícitamente en la intención de convencimiento de su propia argumentación (34).

¿En qué reside ahora la significación filosófica de este recurso al discurso argumentativo como la forma reflexiva de la comunicación

(34) Este argumento parece haber sido comprendido ya por Platón en sus diálogos socráticos -así en el Georgias y en el libro I de la Politeia-, como argumento en el sentido de la autorrefutación de quienes sostienen pretensiones de poder mediante la discusión. Cfr. para esto: V. Hösle, Wahrheit und Geschichte, StuttgartBad Cannstatt, 1984, pp.334.ss. 
humana? ¿Se trata acaso solamente de una complicación pedante de la intuición fundamental de una "teoría de la acción comunicativa"? Yo pienso más bien que con esto queda indicada de hecho la necesidad de una reinterpretación pragmático-trascendental de la TAC. Los alcances de esta reinterpretación quiero señalarlos aquí solamente en forma de tesis. Según mi modo de ver se puede mostrar lo siguiente:

La completa "arquitectónica" de la TAC solamente puede demostrar su validez mediante el rodeo de la reflexión pragmático-trascendental sobre las pretensiones de racionalidad, que han sido ya siempre reconocidas, del discurso argumentativo acerca de los problemas en cuestión, y no inmediatamente, por medio de la reconstrucción empíricamente comprobable de las condiciones del mundo de la vida. Y al hablar de "la completa arquitectónica de la TAC" me refiero tanto a la concepción de su diferenciación ideal-típica entre los diferentes tipos de racionalidad de la acción, como también a la diferencia (igualmente ideal-típica) entre el mundo de la vida (Lebenswelt) de los seres humanos, y el sistema social funcional, cuya tendencia de autoafirmación puede conducir a una "colonización del mundo de la vida". Por cuanto a la diferenciación de los tipos ideales de racionalidad de la interacción no le corresponde por cierto una separación real de las formas de acción en el mundo de la vida, (y presuponer tal cosa llevaría nuevamente a una "idealistic fallacy" de proveniencia cartesiana). Pero además, si se hace posible en absoluto hablar del mundo de la vida de los seres humanos -a diferencia de los mundos de la vida históricamente condicionados que corresponden a las respectivas "formas de vida" socioculturales-, es porque se puede acreditar mediante la reflexión trascendental la posibilidad de justificar en el nivel del discurso argumentativo las "pretensiones de validez universal", las que están por cierto presupuestas en la posibilidad del entendimiento de todos los hombres a través del lenguaje.

(Frente a quiénes, con Wittgenstein o Lyotard (35), afirman también en el nivel del discurso filosófico la inconmensurabilidad de los

(35) Cfr. J.F.Lyotard, Das postmoderne Wissen, Bremen, 1982, y Der Widerstreit, München, 1987. 
múltiples juegos de lenguaje, se puede mostrar la unidad del discurso por el hecho que bajo tales presupuestos la propia tesis de la inconmensurabilidad no se podría enunciar con sentido. Esto es así por cuanto para poder enunciar dicha tesis se debe presuponer la posibilidad de un juego de lenguaje en el cual uno puede hablar con validez sobre la inconmensurabilidad de todos los juegos de lenguaje).

Lo metódicamente irrebasable (Nichthintergehbare) en la filosofía no es, por cierto, la solitaria conciencia reflexiva del "yo pienso", (en el sentido de Descartes, y aún de Husserl), la cual presuntamente habría extraído sus principios de la pura reflexión fuera del contexto del ser-en-el-mundo y de la comunicación pública a través del lenguaje -en esto estoy yo enteramente de acuerdo con Habermas. Pero sin embargo lo metódicamente irrebasable no es tampoco simplemente el prerreflexivo ser-en-el-mundo (Heidegger, Merlau-Ponty), o bien la praxis de la acción comunicativa en el mundo de la vida (36), sino la praxis de la comunicación consensual en tanto ella se comprende a sí misma, en el nivel del discurso argumentativo, como aquello detrás de lo cual no se puede retroceder ya mediante la reflexión (als reflexiv nichthintergehbar). En esto, y no en el simple regreso al mundo de la vida, a la vida, a la praxis, o al lenguaje reside, según mi modo de ver, la legítima transformación del punto de vista de la tradicional filosofía trascendental de la conciencia, o sea, del solipsismo metódico. De esta manera, la fundamentación última de todos los criterios de validez, es decir, de las condiciones de posibilidad de la resolución de las pretensiones de validez que se juegan en el uso del lenguaje, tiene que producirse de hecho, según mi modo de ver, de manera siempre todavía "quasi" idealista, en cierto modo verticalmente desde arriba. Precisamente entonces puede la filosofía ser al mismo tiempo realista, es decir, puede situarse frente a la realidad con serenidad (Gelassenheit) -teoréticamente con la requerida disponibilidad para la falsación y prácticamente con la requerida capacidad de resistencia a la frustración. Y se puede entonces reconocer incluso que los

(36) Así Habermas en Kommunikatives Handeln (cit. más arriba en nota 24), p. 368 . 
contenidos concretos de sentido de la vida no son constituidos jamás solamente mediante una pura conciencia y sus funciones de síntesis sino que, -en tanto ellos están condicionados al mismo tiempo por intereses y necesidades-, se constituyen más bien desde abajo, en el contexto histórico de la praxis cotidiana de la vida. No se trata por lo tanto ya de la alternativa metafísica entre idealismo y materialismo, sino más bien de una visión que Charles Peirce ha formulado de la manera siguiente: "El materialismo sin idealismo es ciego, el idealismo sin materialismo es vacío".

Volvamos ahora, a partir de este resultado, a nuestro problema de la explicitación del significado lingüístico, e intentemos extraer las consecuencias. Con la radicalización del planteo de la pragmática universal mediante la reflexión trascendental parece quedar demostrado que la "fuerza ilocucionaria del habla" -es decir, el significado lingüístico en el sentido de la "indicación performativa" del significado pragmático de los actos de habla-, conforme a sus propias determinaciones tiene que apuntar a una explicitación en los términos de validez justificable de manera consensual comunicativa. Por cuanto la comprensión de la "fuerza ilocucionaria" de actos de habla en el sentido de las pretensiones de poder presupone -como se ha visto- en el nivel irrebasable de la reflexión del discurso argumentativo, que nosotros, con la diferencia entre mera pretensión de poder y pretensión de validez consensualmente justificable, hemos reconocido al mismo tiempo ya también la dependencia parasitaria de la comprensión del sentido de las pretensiones de poder con respecto a la comprensión del sentido de pretensiones de validez susceptibles de justificación. Esta última comprensión de significado está ya siempre presupuesta y reconocida en toda comprensión de significado como la fundamentación racional decisiva para la aceptación de "pretensiones" en general de los seres humanos.

(De ello se sigue, en el nivel de una teoría filosófica de la racionalidad, que no es posible aceptar que la racionalidad instrumental medio-fin, que determina la referencia de la acción humana al mundo en el sentido de la relación sujeto-objeto, se pueda transferir sin más a la referencia en el sentido de la relación sujeto-cosujeto. La racionalidad instrumental medio-fin no es, como se supone generalmente, 
la forma fundamental de la racionalidad de la acción en general, a partir de la cual se podrían o se deberían comprender también las intenciones de sentido de los seres humanos, expresadas mediante el lenguaje, en el nivel de la comunicación. Ni siquiera la racionalidad estratégica de la interacción y la comunicación humana, que se ha producido de hecho, genéticamente, mediante la transferencia (ingenua o intencional) de la racionalidad instrumental a la relación sujeto-cosujeto, se puede hacer inteligible sobre la sola base de esa transferencia. Por cuanto ella presupone también ya la reciprocidad de las acciones instrumentales (que no es pensable en el sentido de la relación sujeto-objeto). Y como condición de esa reciprocidad de la interacción estratégica se presupone también, por principio, la posibilidad del entendimiento comunicativo con los otros a través del lenguaje -incluso del entendimiento sobre propósitos estratégicos! (37).

Solamente la Racionalidad consensual comunicativa de ese entendimiento a través del lenguaje -que no es reducible a racionalidad instrumental o estratégica se demuestra, en cuanto racionalidad del discurso, como presupuesto no rebasable de la comprensión y de la fundamentación o justificación de toda racionalidad humana (38).

\section{RESUMEN}

I. Introducción: el horizonte verificacionista de la explicación del significado de las oraciones constatativas en la filosofía analítica del lenguaje.

II. La aporética de la explicación verificacionista del significado en la filosofía analítica del lenguaje.

(37) Cfr. K.-O. Apel. "Lässt sich ethische Vernunft von strategischer Zweckrationalität unterscheiden. Zum problem der Rationalität sozialer Kommunikation und Interaktion", en Archivio di Filosofia, Ll, (1983), p. 375-434. Aparecido también en: W. Van Reyen/K.-O. Apel (Hrsg.), Rationales Handeln und Gesellschafistheorie, Bochum, 1984, p. 23-80, Hay trad. castellana en K.-O. Apel, Estudios Eticos, Edit. Alfa, Barcelona, 1986, pp. 27-104.

(38) Cfr. K.-O. Apel, "Die Herausforderung der totalen Vernunftkritik und das Programm einer philosophischen Theorie der Rationalitätstypen", en Concordia, 11 (1987), p. 2-23. Hay trad. cast. en op.cit., en nota anterior, p. 9-26. 
II. 1. Explicación del significado ilocucionario de las oraciones o actos de habla no constatativos en los términos de "condiciones de realización". -Sobre la aporética del paradigma verificacionista en P. Strawson.

11. 2. Explicación del significado ilocucionario de las oraciones o de los actos de habla no constatativos en términos de las "condiciones de satisfacción" referidas a intenciones. -Sobre la aporética del paradigma verificacionista en J. R. Searle.

III. La explicación pragmática universal o trascendental del significado ilocucionario de las oraciones o actos de habla en términos de las condiciones de validez.

III. 1. El planteo de la pragmática universal sobre la explicación del significado ilocucionario en términos de aceptabilidad de las pretensiones de validez (consensualmente rescatables) y el problema residual de la aceptación fáctica de las pretensiones ilocucionarias de poder.

III. 2. La solución habermasiana del mencionado problema residual mediante la comprobación de la "dependencia parasitaria" del uso encubiertamente estratégico del lenguaje con respecto al uso del lenguaje orientado al entendimiento y el nuevo problema residual del uso abiertamente estratégico del lenguaje.

III. 3. La resolución del problema residual del uso abiertamente estratégico del lenguaje por medio del recurso a la reflexión pragmático trascendental sobre las presuposiciones del discurso argumentativo. 